Heat Transfer Research, 2010, Vol. 41, No. 6

\title{
Turbine Aero-Heat Transfer Studies in Rotating Research Facilities
}

\author{
CENGIZ CAMCI \\ Turbomachinery Aero-Heat Transfer Laboratory, \\ Department of Aerospace Engineering, \\ The Pennsylvania State University, 233 Hammond Building, \\ University Park, PA, 16802
}

The present paper deals with the experimental aero-heat transfer studies performed in rotating turbine research facilities. Turbine heat transfer research had significant progress in the last few decades. Since the full-scale operational conditions of a modern gas turbine dictate high temperatures well in excess of $3600^{\circ} \mathrm{F}$ and pressure ratios ranging from 20 to 50 , experimental forced convection heat transfer research on the gas side of a rotating turbine environment is a technically challenging task. The current paper provides a limited review of turbine heat transfer research in various facilities including short-duration blow-down and large-scale/low-speed turbine systems. Since the final status of any forced convection heat transfer problem is closely related to the detailed structure of momentum transfer in highly 3D, unsteady, rotating, and turbulent viscous flow environment, emphasis will also be placed on pertinent turbine aerodynamic features existing in turbines. The most significant parameters to simulate in a rotating aero-heat transfer facility can be listed as Reynolds number based on the blade chord, Mach number for compressibility and shock wave effects, tip speed, intensity and scale of free-stream turbulence, Strouhal number for the unsteady wake passing effects, free-stream to wall temperature ratio, coolant to free-stream temperature ratio, specific heat ratio, molecular Prandtl number of the operating gas and a rotation number for turbine aero-heat transfer work performed under rotational conditions. A flow coefficient and a loading coefficient defined by the actual turbine hardware are typically maintained during laboratory testing.

\footnotetext{
*Address all correspondence to Cengiz Camci E-mail: cxc11@psu.edu
} 
Keywords: gas turbines, convective heat transfer, casing heat transfer, rotating turbine research rigs, realistic gas turbine heat transfer testing.

\section{INTRODUCTION}

The experimental rotating research rigs for gas turbine aero-heat transfer studies range from full-scale gas turbine demonstrators to short duration facilities, from rotating coolant passage simulators to large-scale/low speed turbine research facilities, from rotating disk cavity research rigs to tip leakage flow simulators. While instrumented full-scale gas turbine demonstrators are excellent candidates to generate very realistic gas turbine heat transfer data, the initial investment made to construct them, their extremely high operational costs and the technological challenges in performing reliable and high-resolution aero-thermal measurements limit their current use.

The short duration facilities or blow down type rigs have been extremely popular choices mainly because of their relatively reduced cost of operation and excellent scaling available for Mach number and Reynolds number sensitive aero-thermal phenomena. Although they may not operate at a full-scale gas temperature, they can generate an accurately measurable amount of heat transfer from the gas side to turbine blades in a linear cascade, annular cascade or turbine stage arrangement where there is usually a realistic rotor operation. The heat transfer coefficients resulting from short duration rotating rigs are considered to be reasonably high quality in terms of experimental uncertainties. Although heat transfer instrumentation in short duration facilities require advanced heat flux sensor making, signal transmission and signal processing capabilities, the results generated in these facilities have extremely high technical value, during and after a turbine design sequence. The most visible short duration heat transfer facilities were constructed and operated by Oxford University, Von Karman Institute for Fluid Dynamics, Ohio State University (Calspan previously), MIT Gas Turbine Lab, Wright Patterson Air Force Base and QinetiQ Corporation.

Large-scale and low speed research facilities are also frequently employed in aeroheat transfer research because of their low operating costs, their high reliability and operational safety characteristics. One of the first low speed turbine research rigs was operated by United Technologies Research Center at Connecticut. The currently operational low speed, large-scale turbine research rigs are at the Aero-Heat Transfer Laboratory of the Pennsylvania State University, Purdue University and Texas A\&M University. There are also a number of low-speed/large-scale turbine research facilities currently operational in Germany and Switzerland mainly used for the improvement of stage aerodynamic features.

The current paper provides an overview of presently operational turbine heat transfer research facilities that have a fully operational rotor. In addition to major rotating rigs, the research results from the Axial Flow Turbine Research Facility (AFTRF) at Penn State, operated by the author of this paper will be presented. Since the final 
status of any forced convection heat transfer problem is determined by the detailed structure of momentum transfer in highly unsteady, rotating and turbulent viscous flow environment, emphasis will be placed on pertinent turbine aerodynamic features existing in rotating facilities.

\section{CURRENT GAS SIDE HEAT TRANSFER ISSUES}

The ten major remaining issues in gas turbine aero-thermal research today were presented by Bunker [1]. He mentioned that effective solutions to these ten issues are required to address the remaining gas turbine problems, in realizable engineering. Figure 1 shows a general classification of the challenging problems. The present day gas turbine heat transfer technology usually meets the strict requirements of modern gas turbine engines. The improvements in this technology in the areas of efficiency and life came with small increments over a long duration. The last significant achievements in the technological plateau reached today was the widespread application of shaped film cooling holes and the implementation of thermal barrier coatings. More recent advancements in the last few years were in the area of the understanding of detailed flow physics and in the development and use of advanced analytical/computational analysis tools for aero-thermal problems in the gas side of turbine engines. Bunker [1] considers several important questions to be answered in pushing aero-thermal technology further. His first question is whether to cool a component only at selected hot spots or globally as a whole component. Whether the overall shielding performance against incident heat load could be improved over the level reached by TBCs is his second question. He considers maintaining a component temperature closer to hot gas temperature as one way of minimizing the heat loads from the gas

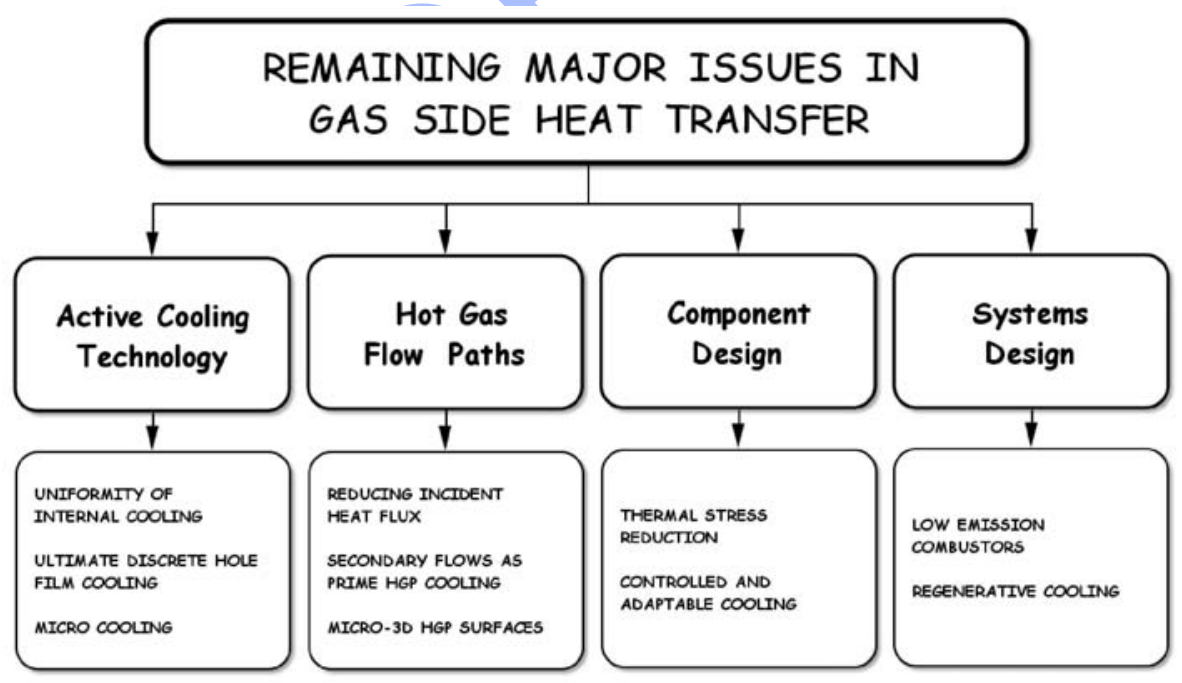

Fig. 1. Major gas side heat transfer issues in turbines [1]. 
side. A more isothermal component is likely to contain a less significant internal thermal stress field. Most modern turbine systems are effectively cooled and they usually operate well above the maximum allowable material temperature. High heat loads in modern systems and a simultaneous implementation of effective cooling result in higher through wall thermal gradients and higher in plane thermal gradients. Moving the thermal energy to somewhere else and dealing with it at its new location is also considered in [1]. A comprehensive treatment of convective heat transfer and aerodynamics in axial flow turbines can be found in an IGTI Gas Turbine Scholar Lecture by Dunn [2].

\section{RESEARCH SIMULATION ISSUES}

Proper scaling of the gas turbine operating environment requires the replication of Reynolds number, molecular Prandtl number of the gases, Mach number, wall to freestream temperature ratio, specific heat ratio of the gases. The simulation parameters listed here can be directly obtained from the nondimensional forms momentum conservation equation and thermal energy equation:

$$
\rho^{*} \frac{\partial V_{i}^{*}}{\partial t^{*}}+\rho^{*} V_{j}^{*} \frac{\partial V_{i}^{*}}{\partial x_{j}^{*}}=-\frac{\partial p^{*}}{\partial x_{i}}+\frac{1}{\operatorname{Re}} \frac{\partial^{2} V_{i}^{*}}{\partial x_{j}^{*} \partial x_{j}^{*}},
$$

where

$$
\begin{gathered}
\operatorname{Re}=\frac{\rho_{0} V_{0} L}{\mu_{0}}=\frac{V_{0} L}{v_{0}}, \\
\rho^{*} c_{p}^{*} \frac{D T^{*}}{D t^{*}}=\frac{V_{0}^{2}}{\left(T_{\mathrm{w}}-T_{0}\right) c_{p_{0}}} \frac{D p^{*}}{D t^{*}}+\frac{k_{0}}{V_{0} \rho_{0} c_{p_{0}}} \nabla^{2} T^{*}+\frac{\mu_{0} V_{0}}{L \rho_{0} c_{p_{0}}\left(T_{\mathrm{w}}-T_{0}\right)} \Phi^{*},
\end{gathered}
$$

where $\Phi^{*}=\Phi / \mu V^{2} / L^{2}$ is the nondimensional viscous dissipation rate. Viscous dissipation rate in its dimensional form is defined as follows:

$$
\begin{gathered}
\Phi=\mu \cdot\left[2\left(\frac{\partial u}{\partial x}\right)^{2}+2\left(\frac{\partial v}{\partial y}\right)^{2}+2\left(\frac{\partial w}{\partial z}\right)^{2}+\left(\frac{\partial v}{\partial x}+\frac{\partial u}{\partial y}\right)^{2}+\left(\frac{\partial w}{\partial y}+\frac{\partial v}{\partial z}\right)^{2}+\left(\frac{\partial u}{\partial z}+\frac{\partial w}{\partial x}\right)^{2}\right] \\
+\lambda\left(\frac{\partial u}{\partial x}+\frac{\partial v}{\partial y}+\frac{\partial w}{\partial z}\right)^{2}
\end{gathered}
$$

The final form of the energy equation as shown in Eq. (4) indicates that for a proper simulation of energy transfer in any environment, where forced convection heat transfer is significant, one needs to simulate Reynolds number, Prandtl number, and Eckert number [Q1]: 


$$
\rho^{*} c_{p}^{*} \frac{D T^{*}}{D t^{*}}=E c \cdot \frac{D p^{*}}{D t^{*}}+\frac{1}{\mathrm{Re} \cdot \operatorname{Pr}} \nabla^{2} T+\frac{E c}{\operatorname{Re}} \cdot \Phi,
$$

where

$$
E c=\frac{V_{0}^{2}}{\left(T_{\mathrm{w}}-T_{0}\right) c_{p_{0}}} \text { and } \operatorname{Pr}=\frac{\mu_{0} c_{p_{0}}}{k_{0}} .
$$

The Eckert number represents the ratio of the kinetic energy of the mean flow to the thermal energy carrying capability of the molecular domain. The Eckert number may be easily substituted with "free-stream gas to wall temperature ratio", the Reynolds number and Mach number in the region of interest. The equation of state $p_{\infty}=\rho R T_{\infty}$ and the local speed of sound $a=\sqrt{\gamma R T_{\infty}}$ can be re-arranged to show [Q2]. On re-arrangement, the Eckert number can be expressed as follows:

$$
E c=\frac{\frac{V_{0}^{2}}{a^{2}}}{\frac{\left(T_{w}-T_{0}\right) c_{p_{0}}}{c_{p_{0}}(\gamma-1) \cdot T_{\infty}}}=(\gamma-1) \cdot M^{2} \cdot \frac{T_{\infty}}{\left(T_{w}-T_{0}\right)}=(\gamma-1) \cdot M^{2} \cdot \frac{\frac{T_{\infty}}{T_{0}}}{\left(\frac{T_{w}}{T_{0}}-1\right)}
$$

where $T_{0} / T_{\infty}=\left[1+(\gamma-1) M^{2}\right]$. The final form of the energy equation suggests that one needs to simulate the Eckert number by operating at a realistic Mach number $\mathrm{M}$, free-stream to wall temperature ratio $T_{\infty} / T_{\mathrm{w}}$ and specific heat ratio $\gamma$. This condition is in addition to $\mathrm{Re}$ and $\mathrm{Pr}$, "for proper simulation ability" in a forced convection heat transfer problem. Simulation for a gas turbine environment also needs to include a proper mass flow function $\dot{m} \sqrt{R T_{0}} / D^{2} P$, corrected speed $N D / a_{0}=N D / \sqrt{\gamma R T_{0}}$, and a rotation number that is also called as the Rossby number Ro $=U / \Omega D$. The last set of requirements directly results from a dimensional analysis effort performed on stagnation enthalpy change, power output and efficiency of a turbomachinery system.

The scaling issues discussed up to this point only considered a laminar flow environment in a momentum and convective heat exchange problem. In a modern gas turbine, combustor exit flow contains a significant amount of turbulence and free-stream unsteadiness. The turbulence intensity and length scale of turbulence are the two parameters that should be considered very carefully. The rotor blades of a gas turbine continuously pass through the highly turbulent and low axial momentum wakes of nozzle guide vanes generating a highly unsteady flow in the rotor passages. In nozzle guide vanes with a transonic/supersonic exit flow, the rotor blades may also chop through shock waves originating from the NGV trailing edges. In the relative flow environment of the rotor exposed to hot gases, blade surfaces see the periodic passing of NGV wakes, shock waves and high momentum fluid originating from the central sections of the upstream passage. The wall shear stress generation on gas turbine surfaces and heat transfer to these surfaces is highly three-dimensional and unsteady. When the gas turbine is film cooled, the typical additional scaling parameters are the blowing rate that is the coolant to free-stream mass flux rate ratio $M=\rho_{c} U_{c} / \rho_{\infty} U_{\infty}$ 
and the coolant to free-stream temperature ratio $T_{\mathrm{c}} / T_{0}$. The ratio of the coolant to free-stream momentum flux rate is also a popular cooling performance parameter $I=$ $\rho_{c} U_{c}^{2} / \rho_{\infty} U_{\infty}^{2}$. A mass flow rate ratio of the coolant to free-stream $\dot{m}_{c} / \dot{m}_{\infty}$ for a stage or a complete turbine may also be used as a cooling performance indicator.

\section{KEY SIMULATION PARAMETERS}

The most important scaling parameter in a gas turbine heat transfer problem is the free-stream gas to wall temperature ratio. The very high temperature level of gas temperatures in a modern turbine makes full-scale investigations technically challenging and expensive. Figure 2 shows the combustor exit temperature and pressure for a number of advanced gas turbine configurations that are successfully operated in the past. Instead of working with the absolute level of the free stream gas temperature, operating with "the free-stream gas to wall temperature ratio", the momentum transfer and heat transfer in a gas turbine could be effectively simulated under relatively manageable testing conditions. In general, reducing the absolute level of the gas temperature has a very advantageous effect in the design of a turbine test facility. Lowered free-stream gas temperatures require a lower operating pressure when the Reynolds number is fully matched between the actual operation and the test facility.

Lowered gas temperature operation has another significant benefit. The rotational speed of the test facility is also reduced when the absolute level of the gas temperature is reduced. The mechanical stresses on the test facility and rotating instrumentation system are simultaneously reduced simplifying the facility design and operation. The reduction in rotational speed reduces the frequency response requirements of in-

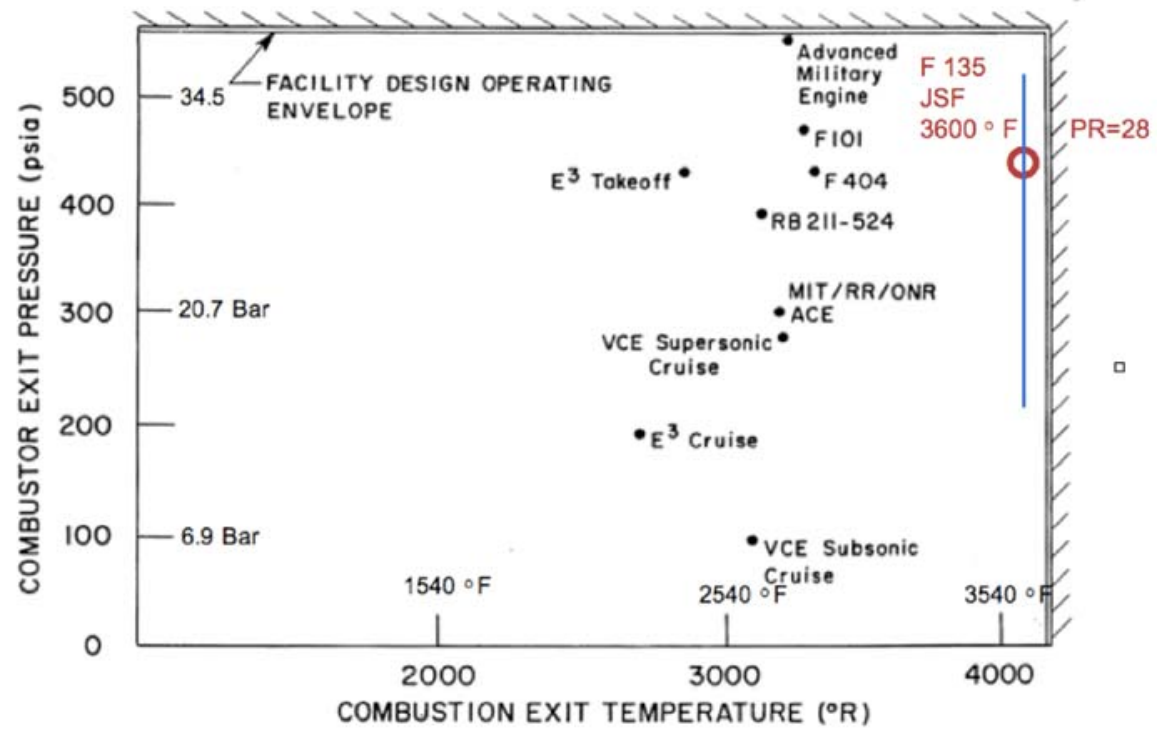

Fig. 2. Typical gas turbine entry temperatures and pressures in existing gas turbine systems. 
strumentation especially for time-accurate and phase-locked measurements in the rotor frame of reference [3]. The measurement of unsteady heat transfer, wall shear stress, aspirating probe measurements for simultaneous total pressure and temperature measurements, hot wire measurements, hot film measurements, time accurate tip clearance measurements, particle image velocimetry measurements and pressure sensitive paint measurements all fall into a category that benefits from relatively reduced frequency response operation at lowered rotational speed in facilities realistically simulating present day turbines.

Although the low speed operation of a research turbine may not be sensitive to the specific heat ratio $\gamma=c_{p} / c_{\mathrm{v}}$, a proper matching of this fluid property cannot be ignored for transonic and supersonic turbines. The specific heat ratio $\gamma$ is a strong property of the gas composition that can be adjusted by using a combination of low and high $\gamma$ molecules. Increasing the molecular weight of the gases in a turbine decreases the operating pressure required at a selected Reynolds number and decreases the speed of sound of the gas thus reducing the turbine rotational speed. The heaviest monatomic gas that is readily available is Argon [3]. For example, a 75\% Argon and 25\% Freon-12 mixture is an ideal composition for scaled turbine testing. Freon-14 itself may be an effective candidate as a turbine cooling gas, however, the usage of Freon is currently restricted due to environmental reasons. The rotational speed of the turbine disk is usually adjusted to keep the corrected speed $N D / \sqrt{\gamma R T_{0}}$ constant. Scaled turbine operation requires an operation at significantly reduced mass flow rate and power level.

\section{AERO-HEAT TRANSFER RESEARCH IN SIMULATED TURBINE RIGS}

The rotating turbine research rigs for aero-heat transfer studies range from fullscale gas turbine demonstrators to short duration facilities, from rotating coolant passage simulators to large scale/low speed turbine research facilities, from rotating disk cavity research rigs to tip leakage flow simulators. While instrumented full-scale gas turbine demonstrators are excellent facilities to generate very realistic gas turbine heat transfer data and performance evaluation; the initial investment made to construct them, their extremely high operational costs and the technological challenges in performing reliable and high-resolution aero-thermal measurements limit their current use.

The short duration facilities have been popular choices because of their relatively reduced cost of operation and excellent scaling available for Mach number and Reynolds number sensitive aero-thermal phenomena. Although they may not operate at a full-scale free-stream gas temperature, they can generate an accurately measurable amount of heat transfer from the gas side to turbine blades. The heat transfer coefficients resulting from short duration rotating rigs are considered to be of high quality in terms of experimental uncertainties. Although heat transfer instrumentation 
in short duration facilities require advanced heat flux sensor making, signal transmission and signal processing abilities, the results generated in these facilities have extremely high technical value, during and after a turbine design sequence. The most visible short duration heat transfer facilities were constructed and operated by Oxford University, Von Karman Institute for Fluid Dynamics, Ohio State University (Calspan previously), MIT Gas Turbine Lab, Wright Patterson Air Force Base Laboratories and QinetiQ Corporation.

Large-scale and low speed research facilities are also frequently used in aero-heat transfer research because of their low operating costs, high reliability and operational safety characteristics. One of the first turbine research rigs was operated at United Technologies Research Center at Connecticut. The currently operational low speed, large-scale turbine research rigs are at the Aero-heat Transfer Laboratory of the Pennsylvania State University, Purdue University and Texas A\&M University. Also there are a number of low-speed/large-scale turbine research facilities currently operational used mainly for the improvement of stage aerodynamic features.

\subsection{A Proposed Blow-down Turbine/Fan Test Facility at UTRC}

A blow-down research facility was designed by UTRC for aero-heat transfer studies in turbines and fans [4]. Although this facility was never built, the design had a unique property of being able to test either a turbine or a fan in a short duration mode. Figure 3 shows the turbine model and fan model connected between a com-
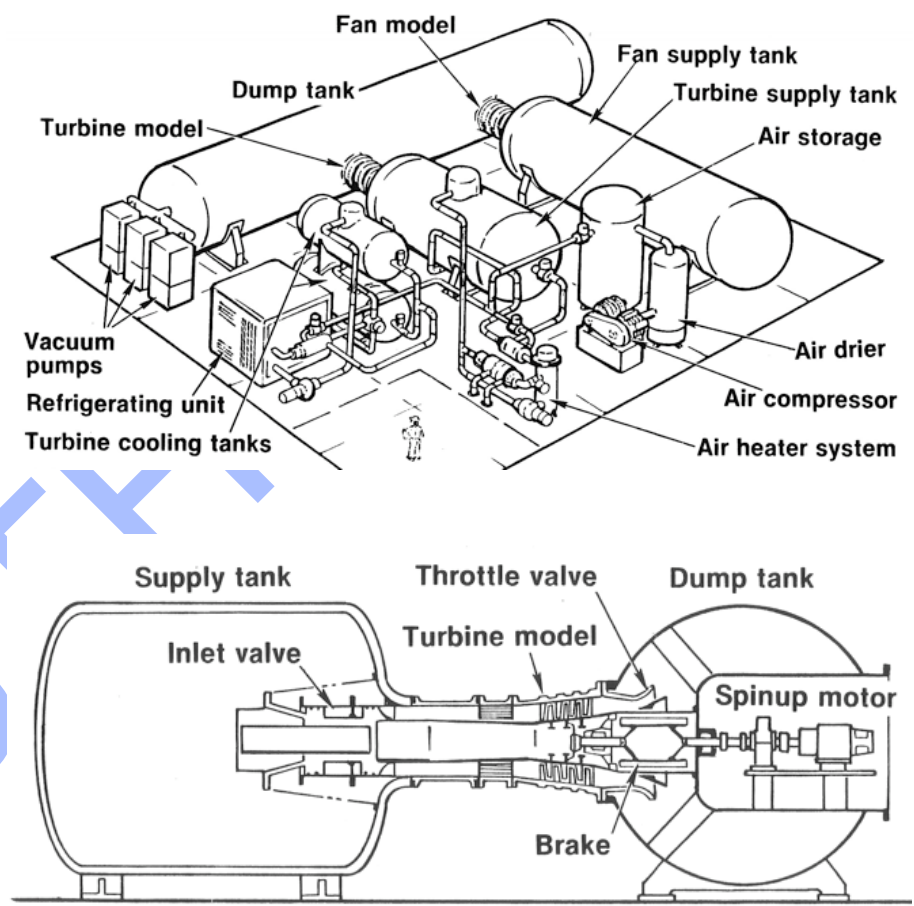

Fig. 3. Proposed turbine/fan test facility at UTRC [4]. 
mon supply tank and a large dump tank. The turbine test section was designed to have a multistage and cooled turbine including an adjustable throttle valve, rotor spinup motor and an eddy-current-brake for torque absorption and speed control. The facility allowed the use of up to 4 turbine stages with a maximum diameter of 37 inches. The quick acting inlet valve operating in less than $50 \mathrm{~ms}$ located inside the supply tank was one of the most important components in this turbine test rig, allowing a total of test duration of 1 second. This 1 -second long test duration included the initial transient disturbances due to quick opening of the inlet valve. The facility inlet had provisions to simulate inlet pressure and temperature profiles and a heat exchanger section for turbine inlet temperature level control. A $100 \mathrm{HP}$ spin up motor located in the initially evacuated dump tank brought the turbine rotor to its rotational speed before the opening of the quick acting inlet valve. The pressure ratio between the supply tank and the dump tank controlled the Mach number simulation in this facility. The level of the supply tank initial pressure and the throttle valve controls the mass flow rate and Reynolds number in the turbine rig. The facility design allowed testing every 20 minutes and had provisions for boundary layer bleed at turbine inlet.

\subsection{MIT Blow-down Turbine Test Facility}

MIT turbine test rig is a short duration facility that is capable of testing filmcooled, high work aircraft engine stages for a typical duration of $400 \mathrm{~ms}$ [5]. This facility can generate test rig conditions that are properly simulating turbine operation up to $40 \mathrm{~atm}$ inlet pressure and $4000^{\circ} \mathrm{F}(2500 \mathrm{~K})$ turbine inlet temperature; the $0.5 \mathrm{~m}$ diameter test facility is intended for the investigation of three-dimensional and unsteady turbine flow and convective heat transfer. A full experimental simulation of a turbine stage including wall to free-stream temperature ratio, coolant to free-stream temperature ratio, Reynolds number, Mach number, Rossby number, corrected speed, weight flow and specific heat ratio is possible in a relatively large diameter stage in which detailed unsteady flow, heat transfer and performance indicating instrumentation is available. Figure 4 shows major turbine design parameters and turbine scaling characteristics and a mid-span blade-to-blade view of the turbine stage. In [5], it is mentioned that the instrumentation access, initial cost and high time response instrumentation are the prime concerns in the design of this facility. The simulation characteristics presented in Fig. 4 indicates that a realistic free-stream gas to wall temperature ratio of 0.63 can be realized at $295 \mathrm{~K}$ for a full-scale operation of $1780 \mathrm{~K}\left(2750^{\circ} \mathrm{F}\right)$. A full-scale coolant temperature level of $790 \mathrm{~K}$ is reduced to 212 $\mathrm{K}$ in the test rig. The lowered free-stream gas temperature in the rig allows a turbine disk operation at almost half speed $(N=6190 \mathrm{rpm})$ of the full-scale operation $(12,734 \mathrm{rpm})$. The MIT blow down turbine facility operates at a turbine inlet total pressure of $4.3 \mathrm{~atm}$ (64 psia) whereas the full-scale hardware runs at $19.6 \mathrm{~atm}$ (289 psia). Other important test rig parameters in comparison to the full-scale hardware are shown in Fig. 4[Q3]. The specific heat ratio $\gamma$ in the facility is adjusted using a com- 
TABLE 1 TURBINE DESIGN PARAMETERS

\begin{tabular}{|l|c|}
\hline Turbine loading, $\Delta \mathrm{H} / \mathrm{U}^{2}$ & -2.3 \\
Total pressure ratio & 4.2 \\
Velocity ratio, $\mathrm{C}_{\mathrm{x}} / \mathrm{U}$ & 0.63 \\
Rotor aspect ratio & 1.5 \\
NGV exit Mach No. & 1.18 \\
\hline
\end{tabular}

TABLE 2

MIT BLOWDOWN TURBINE SCALING

\begin{tabular}{|l|l|l|}
\hline & Full Scale & MIT Blowdown \\
\hline \hline Fluid & Air & Ar-Fr 12 \\
Ratio specific heats & 1.28 & 1.28 \\
Mean metal temperature & $1118^{\circ} \mathrm{K}\left(1550^{\circ} \mathrm{F}\right)$ & $295^{\circ} \mathrm{K}\left(72^{\circ} \mathrm{F}\right)$ \\
Metal/gas temp. ratio & 0.63 & 0.63 \\
Inlet total temperature & $1780^{\circ} \mathrm{K}\left(2750^{\circ} \mathrm{F}\right)$ & $478^{\circ} \mathrm{K}\left(400^{\circ} \mathrm{F}\right)$ \\
True NGV chord & $8.0 \mathrm{~cm}$ & $5.9 \mathrm{~cm}$ \\
Reynolds number* & $2.7 \times 10^{6}$ & $2.7 \times 10^{6}$ \\
Inlet pressure, atm & 19.6 & 4.3 \\
Outlet pressure, atm & 4.5 & 1.0 \\
Outlet total temperature & $1280^{\circ} \mathrm{K}\left(1844^{\circ} \mathrm{F}\right)$ & $343^{\circ} \mathrm{K}\left(160^{\circ} \mathrm{F}\right)$ \\
Prandtl number & 0.752 & 0.755 \\
Eckert number & 1.0 & 1.0 \\
Rotor speed, rpm & 12,734 & 6,190 \\
Mass flow, kg/sec & 49.0 & 16.6 \\
Power, watts & $24,880,000$ & $1,078,000$ \\
Test time & Continuous & $0.3 \mathrm{sec}$ \\
\hline
\end{tabular}

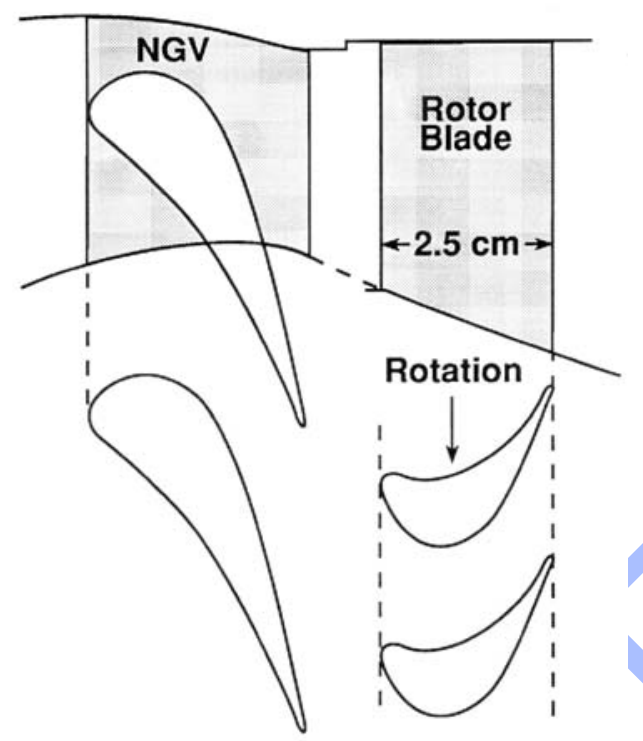

* Based on NGV chord and isentropic exit conditions

$\dagger(\gamma-1) \mathrm{M}^{2} \mathrm{~T} / \Delta \mathrm{T}$

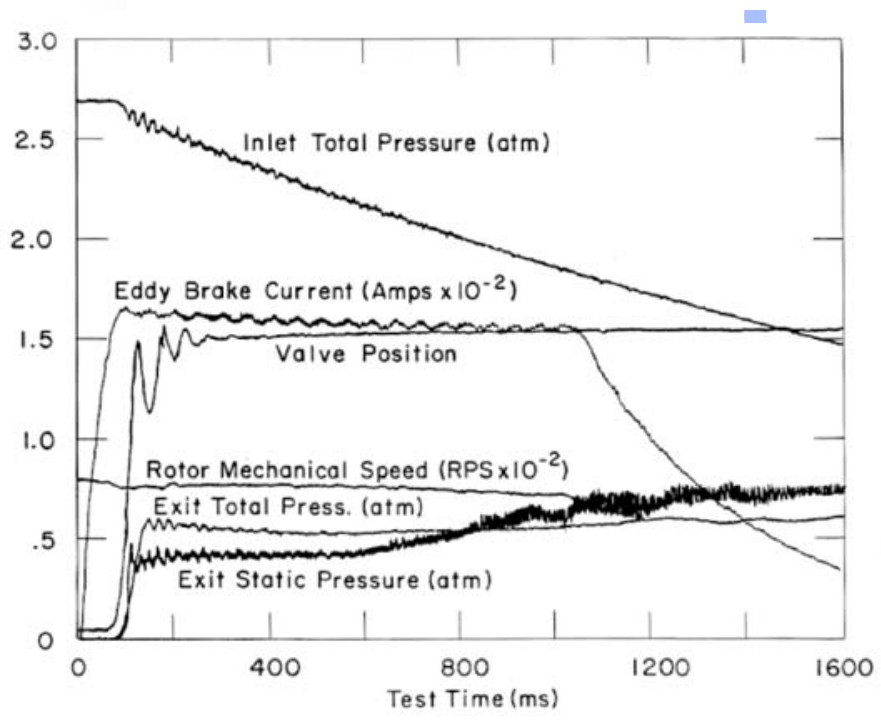

Fig. 4. MIT blow down rig design parameters, turbine scaling, and timing [5].

bination of a monatomic gas Argon and other heavier molecular weight gases that are refrigerant gas mixtures.

The fast opening valve isolating the test section from the supply tank opens fully in $50 \mathrm{~ms}$ and is designed for a supply tank pressure of $10 \mathrm{~atm}$ when the test section is near vacuum conditions. The supply tank temperature can be adjusted to a level as high as $530 \mathrm{~K}$. A $0.9-\mathrm{m}$ diameter annular cone shaped plug seals against the inner and outer annuli of the flow path as shown in Fig. 4. The cone slides forward to open on graphite rings along its shaft to form a smooth annular contraction from the 


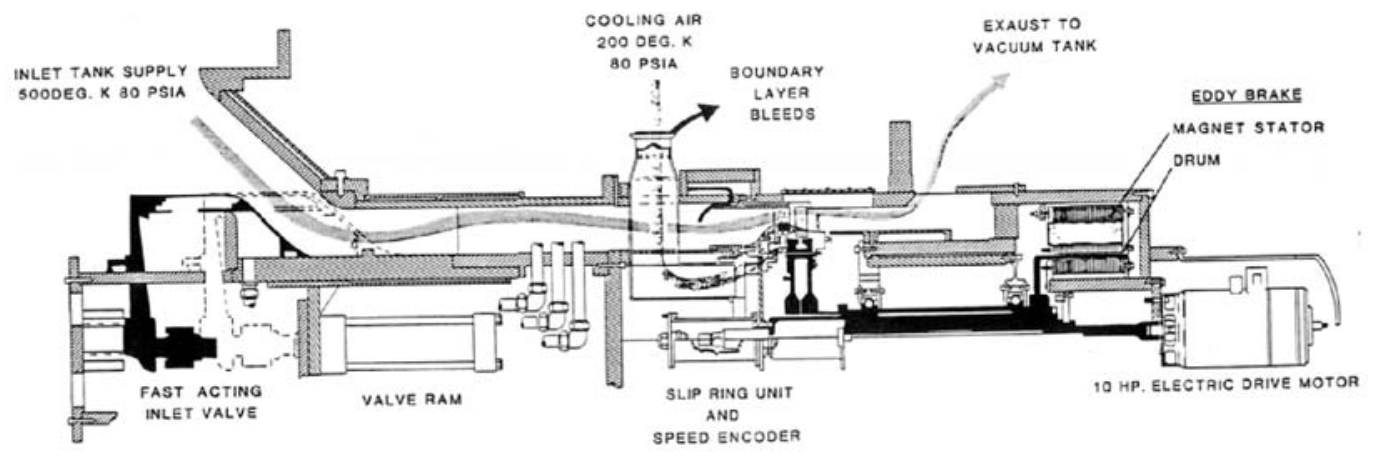

Fig. 5. MIT turbine test section and fast acting inlet valve [5].

supply tank to the test section. The contraction is a part of the boundary layer control system that also includes a boundary layer bleed arrangement. Time resolved turbine rotor blade heat transfer measurements performed in the MIT blow down turbine rig are compared to computations by Abhari et al. [6]. The influence of hardware manufacturing tolerances on rotor heat transfer variation is discussed. A multilayer thin film heat flux gauge using a $25 \mu \mathrm{m}$ thick polyimide insulator is adhesively bonded to the blade profile. The sensing area is limited to $1 \times 1.3 \mathrm{~mm}$. Above $1 \mathrm{kHz}$, the $25 \mu \mathrm{m}$ thick insulator appears infinitely thick to the top surface. The entire frequency domain in heat flux measurements from dc to $100 \mathrm{kHz}$ is reconstructed where the blade passing frequency is $3.6 \mathrm{kHz}$. The heat flux signals are digitized at $100 \mathrm{kHz}$ sampling rate and ensemble averaged for 360 vane-passing periods. The absolute calibration accuracy of the time-accurate heat flux sensors are quoted to be about $10 \%$ [6].

A comparison of the time-averaged measured rotor heat transfer, the unsteady NGV-rotor calculation and the steady state solution for the rotor alone are also compared in Fig. 6 for design incidence. The Nusselt number is defined using the blade axial chord, heat flux, inlet relative total minus local blade temperature and thermal conductivity at blade local temperature. The difference between the steady state turbulent and time averaged unsteady calculations is shown to be minimal. The measured heat transfer rates in general, follows the fully turbulent computation levels. As a whole blade average, the predicted heat transfer rate is about $11 \%$ less than the measured value. Time resolved heat transfer data at design incidence are presented in Fig. 6[Q4] along both the suction and pressure surfaces. The unsteady flow influence on heat transfer signals is shown. Near the stagnation point, the computations using a Baldwin-Lomax turbulence model show a much higher degree of unsteadiness when compared to the measurements. The unsteadiness of heat transfer data is a result of the NGV wake impingement on the rotor blade surfaces and potential coupling that includes moving shock patterns emanating from the NGV trailing edges. A very interesting conclusion from [6] study was that the prediction of heat transfer in highly 

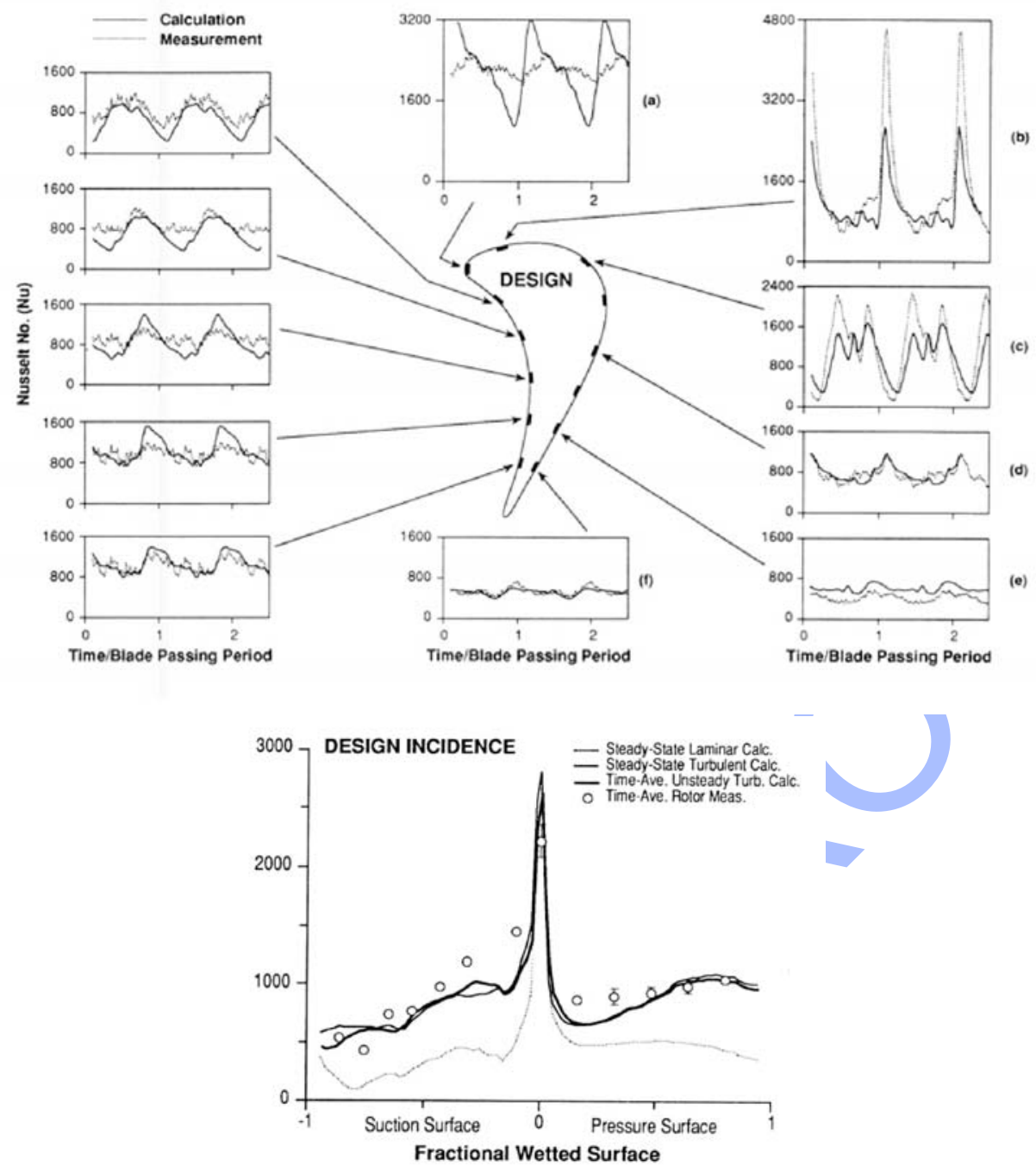

Fig. 6. Rotor blade heat transfer measurements in MIT turbine facility [6].

loaded turbines is more sensitive to the details of the inviscid flow prediction than to the particulars of the turbulence model employed. Another interesting observation in his study was the small difference between the steady fully turbulent rotor calculation and the time average of the unsteady heat transfer calculation. The unsteadiness played a very small role in the specific highly loaded transonic turbine even though both the measurements and computations show very significant unsteady fluctuations in time accurate heat transfer data.

\subsection{UTRC Large-Scale Rotating Rig (LSRR)}

United Technologies Large-Scale Rotating Rig (LSRR) was one of the first rotating turbine research facilities that performed significant amount of aerodynamics and heat 

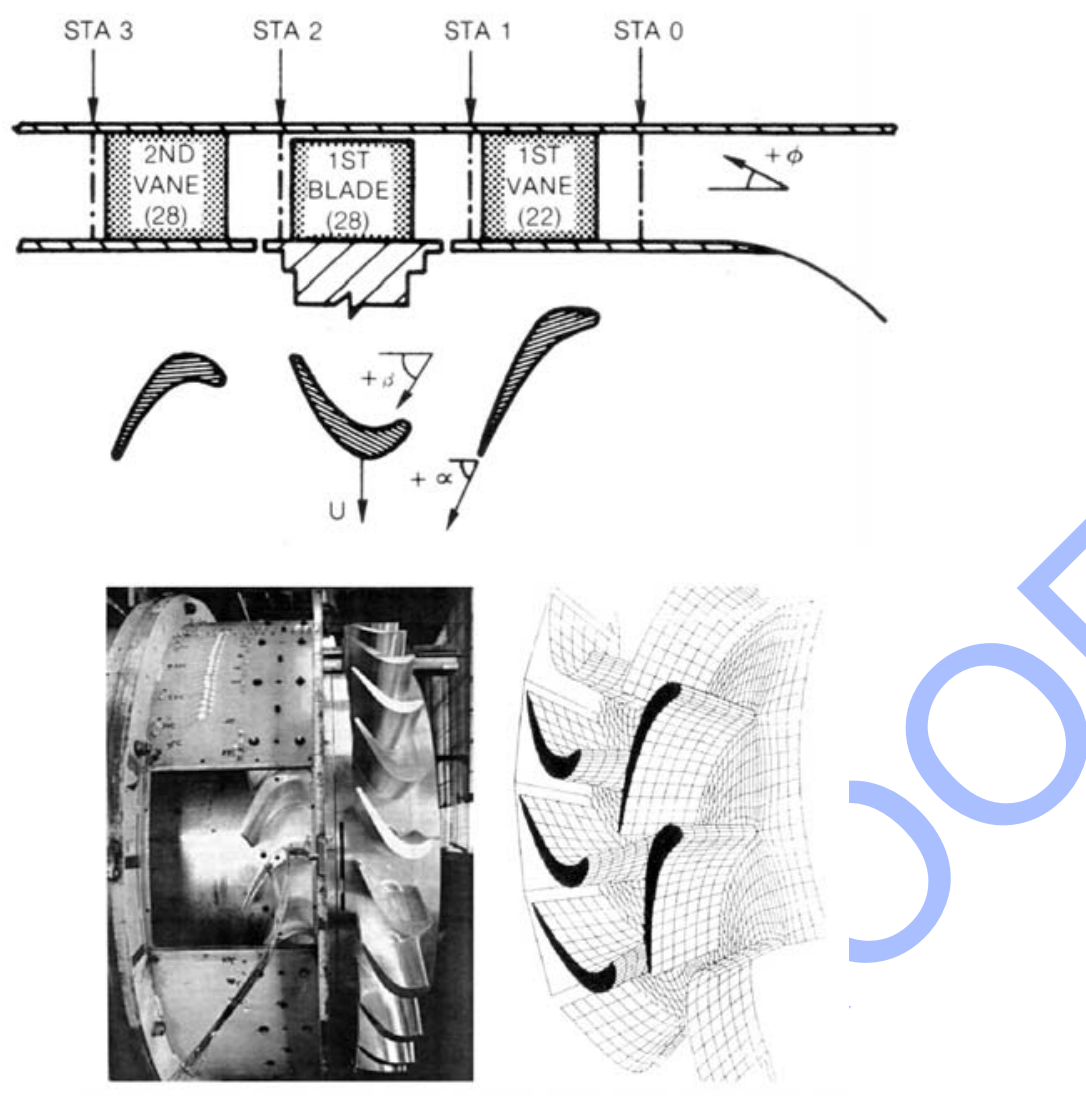

Fig. 7. UTRC Large Scale Rotating Rig (LSRR) [7].

transfer research in a low speed turbine environment where the first three rows of the test rig represented a high by-pass ratio aircraft engine. General characteristics of this rotating test facility are described in [7]. This 1.5 stage low speed facility operated from laboratory air conditions at about $1 \mathrm{~atm}$ inlet total pressure and $294 \mathrm{~K}$ inlet total temperature with a flow coefficient of 0.78 . The experimental turbine having a 0.8 hub/tip ratio had 22 first vanes, 28 first blades, and 28 second vanes. The model airfoil chord lengths were about five times full-scale hardware chord lengths. The rotor speed was about $410 \mathrm{~m} / \mathrm{s}$ and atypical airfoil Reynolds number was approximately 560,000 that were typical of high-pressure turbine airfoils. The effects of turbulence and stator-rotor interactions on turbine heat transfer were studied by Blair et al. $[8,9]$. Figure 8 presents the Stanton number distribution on the suction side of the LSRR rotor blade in comparison to Sharma et al. computations [10]. A very good match between the unsteady computations and rotor heat transfer measurements was shown. An important result from Sharma's unsteady numerical simulations indicated that time-averaged loads on airfoil surfaces (and endwalls) are not influenced by unsteadiness even in the presence of temperature streaks. Unsteady computations clearly show that the pressure sides of turbine airfoils operate at higher temperatures than the suction sides in the presence of circumferentially nonuniform temperature profiles. 

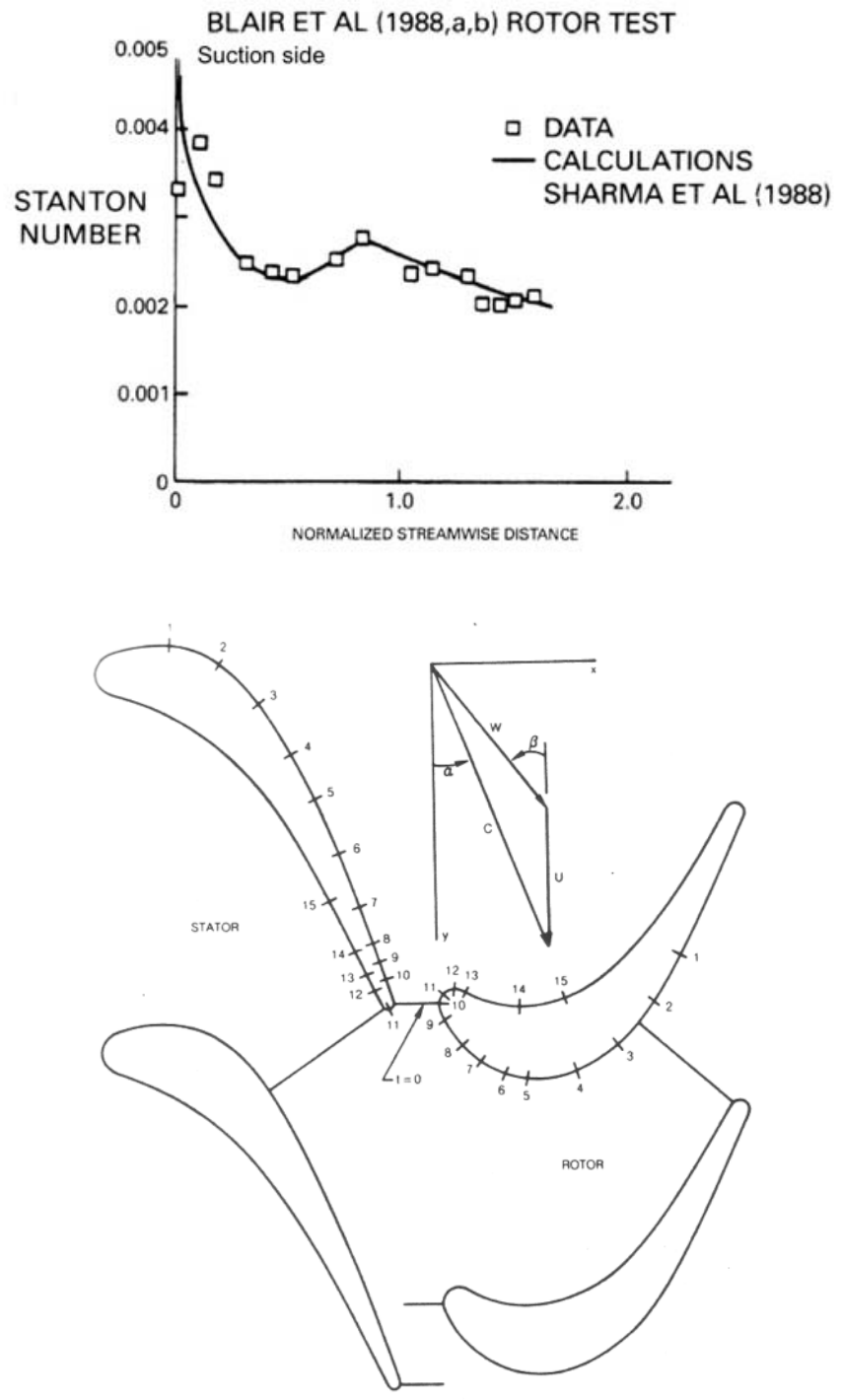

Fig. 8. Comparison of LSRR rotor heat transfer data with computations of [8, 9].

Blair, Wagner and Steuber [11] developed two interesting liquid crystal techniques to obtain steady-state heat transfer data on the gas side of rotating turbine airfoils in LSSR. In one study they developed a liquid crystal-based method to measure heat transfer rates on the rotating blade surfaces. The second study was geared towards heat transfer measurements in rotating turbine coolant passages. Figure 9 shows the sample liquid crystal temperature patterns on the rotor airfoil at two different rotational speeds $(N=407 \mathrm{rpm}$ and $160 \mathrm{rpm})$. This approach used slightly nonrectangular "constant heat flux surfaces" for the measurement of heat transfer coefficients. The deviations from the constant heat flux value due to slightly nonrectangular heater shapes were computed by analytically calculating nonuniform current density func- 

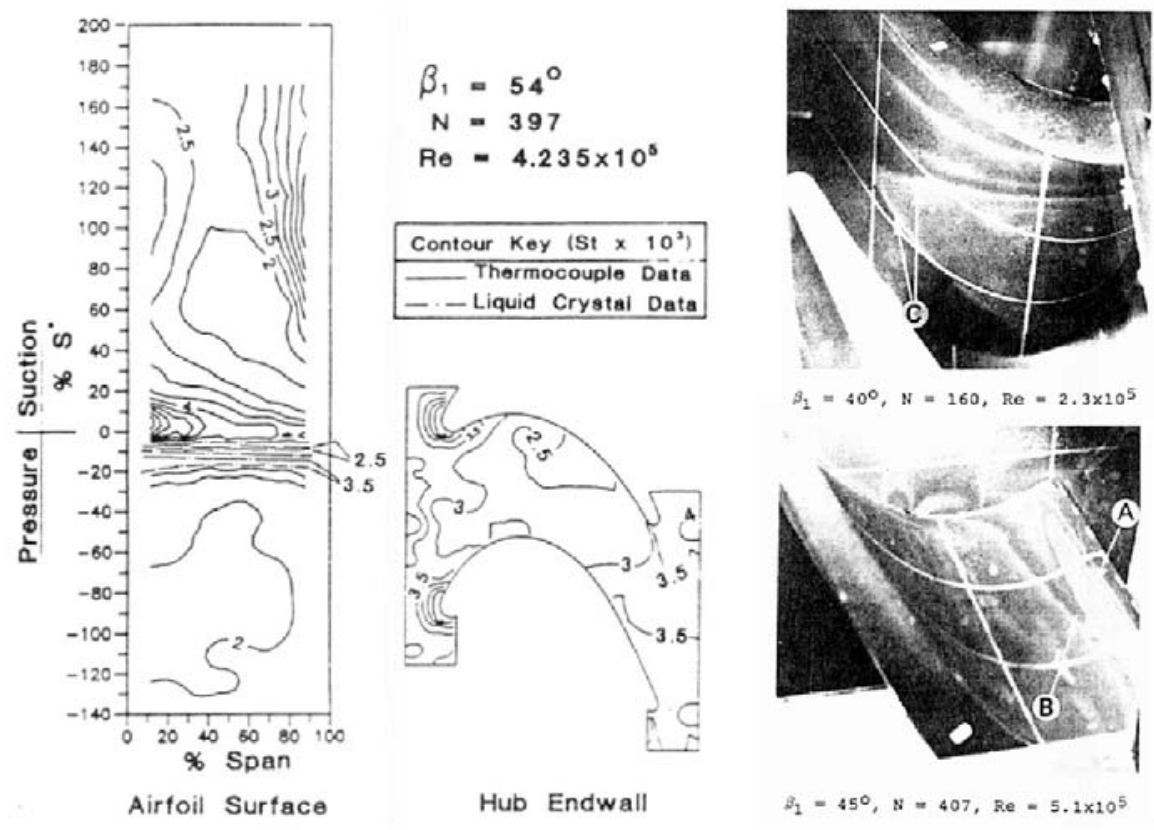

$B_{1}=45^{\circ}, N=407, \operatorname{Re}=5.1 \times 10^{5}$

Fig. 9. Stanton number measurements on the rotor surfaces of LSRR [11].

tions in the actual heater shapes. The liquid crystal images were obtained in the stationary frame of reference by using a strobe light during the passage of the rotor blades. The rotor was instrumented by arrays of 89, 124, and 102 thermocouples on the pressure side, suction and endwall surfaces, respectively. Thermocouple signals and heater electrical connections from the rotor to the stationary frame of reference were transmitted by using a slip-ring device.

Figure 9 shows the contour maps of Stanton numbers on the suction side and pressure side by using a rectangular projection of the unwrapped airfoil surface. Liquid crystal patterns were used to supplement the thermocouple data in regions where extremely localized effects existed. A separation bubble from the heat transfer measurements was clearly visualized. A highly three-dimensional pattern near the suction side, especially near the tip, shows the influence of the tip leakage vortex and the secondary flows on the surface heat transfer distribution. Strong variations in Stanton number contours near the suction side of the leading edge can be attributed to the horseshoe vortex formation due to the momentum deficit in the inlet endwall boundary layer.

\subsection{Turbine Stage in the Oxford Rotor Facility ILPT}

The turbine stage in the Oxford rotor facility as shown in Fig. 10 uses an Isentropic Light Piston compression Tunnel (ILPT) to obtain well simulated gas turbine conditions. Schultz et al. [12] showed that the temperature differences encountered in gas turbine components could be scaled down in light piston compression tube ex- 


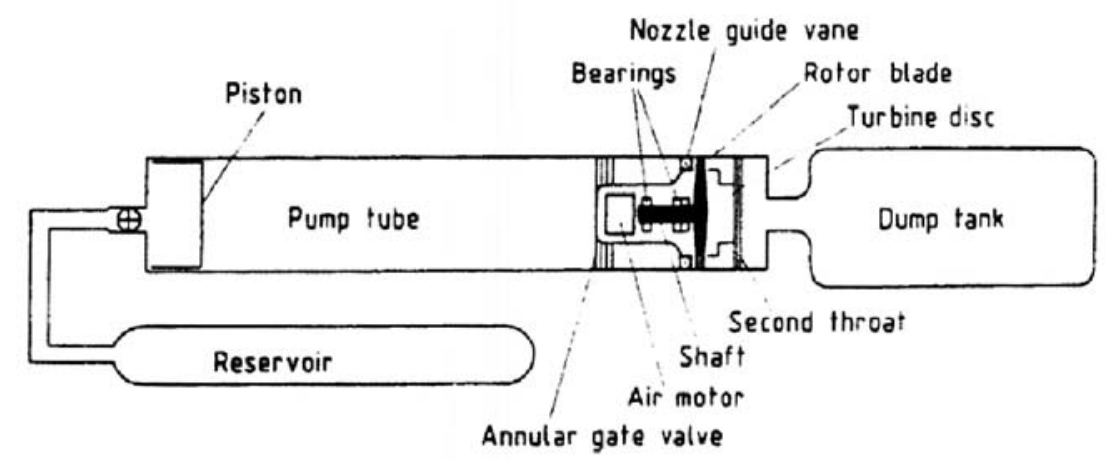

\begin{tabular}{|l|c|l|l|}
\hline \multicolumn{1}{|c|}{ Parameter } & Symbol & \multicolumn{1}{|c|}{ Note } & \multicolumn{1}{c|}{$\begin{array}{c}\text { Design Point } \\
\text { Value }\end{array}$} \\
\hline Rotor Speed & $\mathrm{mm}$ & & 8343 \\
\hline Specific Speed & $\mathrm{N} / \sqrt{\mathrm{T}_{0}}$ & - & $436 \mathrm{RPM} / \mathrm{K}^{1 / 2}$ \\
\hline $\begin{array}{l}\text { Mass Flow } \\
\text { Number }\end{array}$ & $\frac{\mathrm{m} \sqrt{\mathrm{T}_{0}}}{\mathrm{P}_{0}}$ & - & $\begin{array}{l}7.04 \times 10^{-4} \\
\mathrm{~ms} \sqrt{\mathrm{K}}\end{array}$ \\
\hline $\begin{array}{l}\text { Reynolds } \\
\text { Number }\end{array}$ & $\mathrm{Re}$ & $\begin{array}{l}\text { Based on NGV } \\
\text { exit conditions } \\
\text { and axial chord } \\
\text { at mid-height }\end{array}$ & $2.7 \times 10^{6}$ \\
\hline $\begin{array}{l}\text { NGV exit } \\
\text { Mach Number }\end{array}$ & $\mathrm{M}_{\text {exit }}$ & $\begin{array}{l}\text { Isentropic, mid- } \\
\text { height }\end{array}$ & 0.946 \\
\hline $\begin{array}{l}\text { Rotor relative } \\
\text { exit Mach } \\
\text { Number }\end{array}$ & $\mathrm{M}_{\mathrm{r}}$ & $\begin{array}{l}\text { Isentropic, mid- } \\
\text { height }\end{array}$ & 0.959 \\
\hline $\begin{array}{l}\text { NGV Axial } \\
\text { Chord }\end{array}$ & $\mathrm{c}_{\mathrm{NGV}}$ & \multicolumn{2}{|l}{} \\
Ref: Hilditeh [35] & & 0.0312 \\
\hline
\end{tabular}

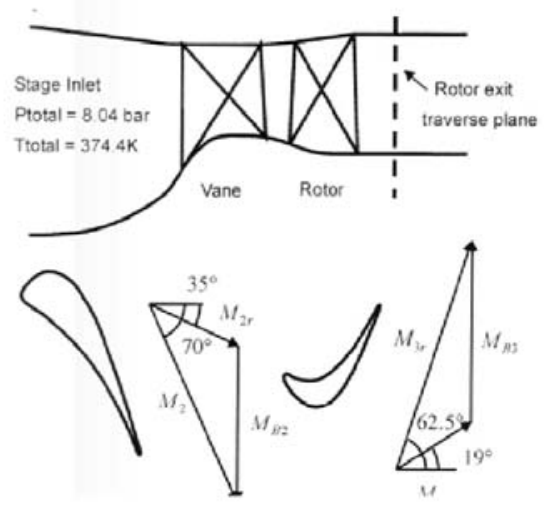

Fig. 10. Turbine stage in the Oxford rotor facility ILPT $[14,15]$.

periments. Hilditch and Ainsworth [13] established the validity of this approach. The turbine stage is a transonic shroudless turbine of $0.5-\mathrm{m}$ tip diameter as explained in [14]. The specific turbine has $36 \mathrm{NGVs}$ and 60 high-pressure turbine blades. The NGV exit Reynolds number is 2,700,000 and the pressure ratio of the turbine is 3.12. The rotational speed of the rotor is $8343 \mathrm{rpm}$ and the blade tip clearance is about $2.25 \%$ of the blade span. Other details of the facility operation and stage schematic are shown in Fig. 10.

Figure 11 shows the mid-span thin film heat flux sensors and a typical heat flux distribution from a pressure surface heat flux sensor. The oscillations in the heat transfer signal are due to the finite weight of the piston used in the compression tube facility. The $180 \mathrm{~ms}$ of the short duration test is shown in the figure. Unsteady heat flux signals from the frontal part of the suction side are presented in Fig. 11. The large fluctuations existing near the leading edge of the suction side start diminishing in magnitude at about $x / S=0.351$. High fluctuation levels are usually explained by the passage of the highly turbulent NGV wakes [15]. Figure 11 shows a double peak from all sensors between $x / S=0.068$ and 0.232 . The spacing between the peaks varies due to upstream motion of the shock emanating from the trailing edge of the 

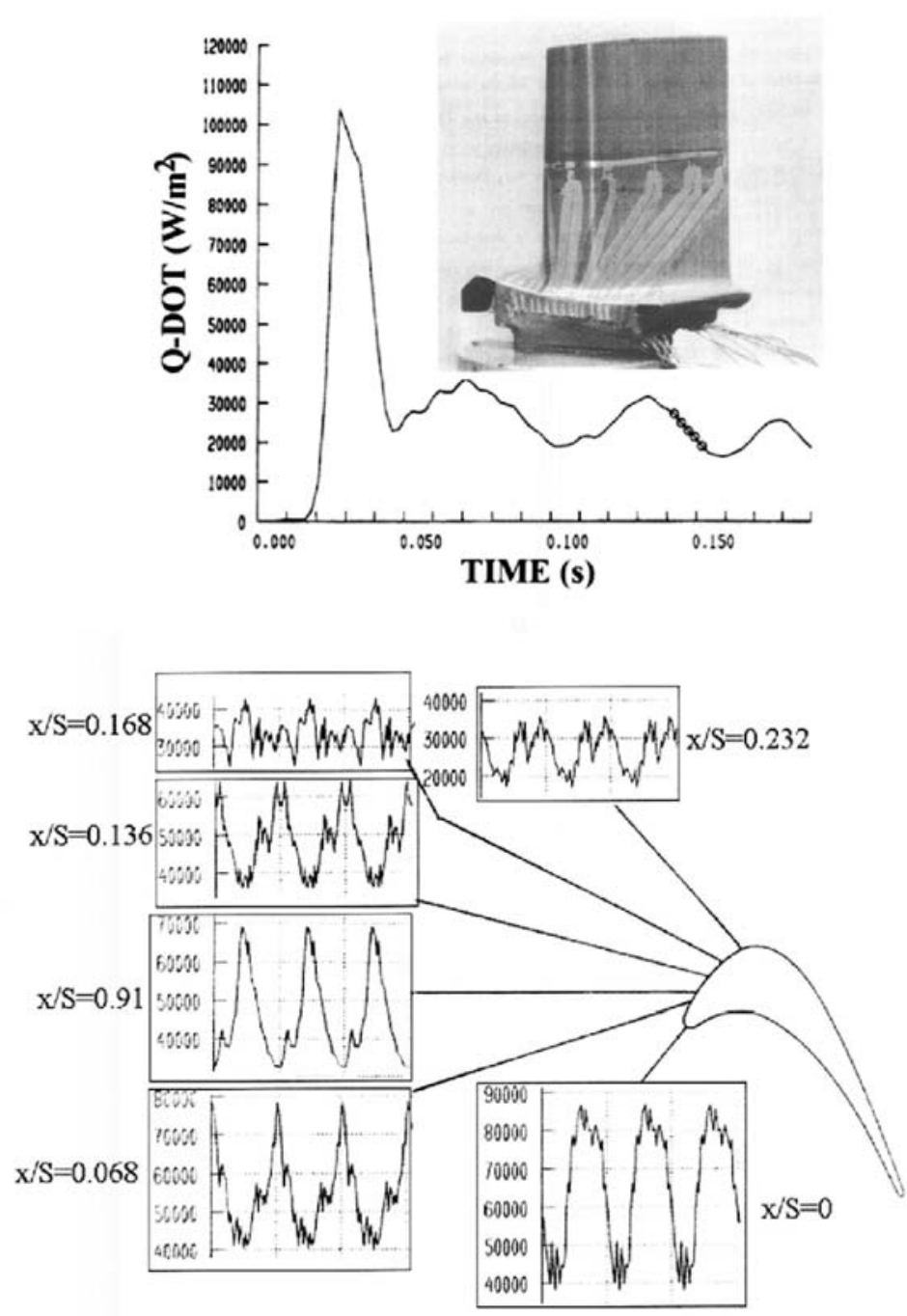

Fig. 11. Unsteady heat flux sensors and heat flux measurements in turbine stage in the Oxford rotor facility ILPT [15].

NGV and the downstream motion of the wake segment. Allan et al. [15] also observed sharp heat flux spikes in heat transfer rate $x / S=0.479$ on the suction side. They attributed the spikes to the presence of reflected trailing edge shocks from the adjacent rotor blade.

\subsection{The VKI Compression Tube Turbine Test Facility CT3}

The VKI research turbine stage shown in Fig. 12 is a representative of a wide class of aero-propulsion engines. The stage is driven by a light piston compression tube facility CT3 that allows the adjustment of the Reynolds number and Mach number, the free-stream to wall and coolant to wall temperature ratios under realistic gas 


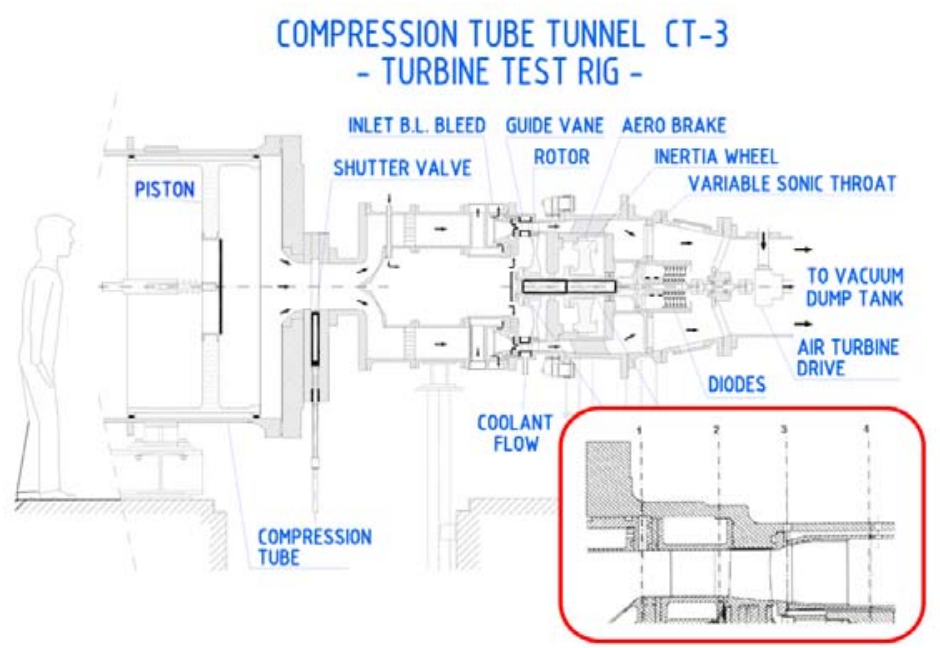

Fig. 12. The VKI turbine research rig $[16,17]$.
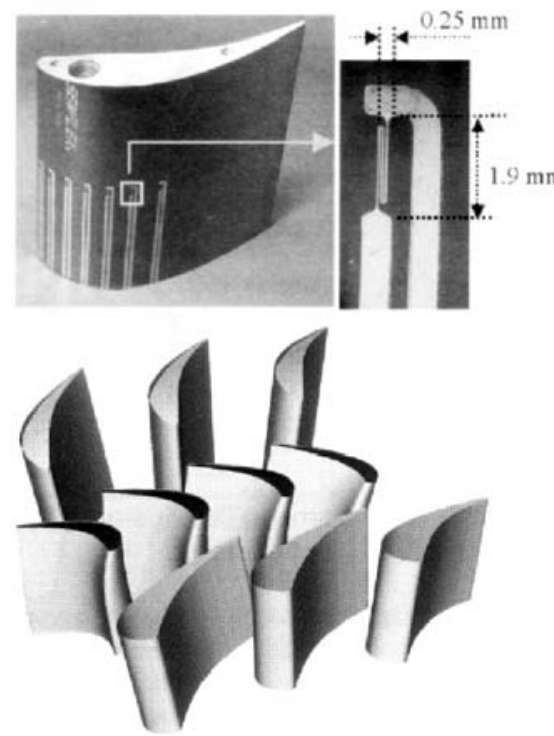

$1 \& 1 / 2$ STAGE FLOW CONDITIONS

\begin{tabular}{|c|c|c|c|}
\hline \multicolumn{2}{|c|}{$\mathrm{P}_{01}[\mathrm{bar}]$} & \multicolumn{2}{|c|}{2.23} \\
\hline \multicolumn{2}{|c|}{$\mathrm{T}_{01}[\mathrm{~K}]$} & \multicolumn{2}{|c|}{480} \\
\hline \multicolumn{2}{|c|}{$\mathrm{P}_{00 /} / \mathrm{P}_{0_{3}}$} & \multicolumn{2}{|c|}{2.63} \\
\hline \multicolumn{2}{|c|}{$\mathrm{P}_{54} / \mathrm{P}_{03}$} & \multicolumn{2}{|c|}{0.72} \\
\hline \multicolumn{2}{|c|}{ Rotational Speed [RPM] } & \multicolumn{2}{|c|}{6500} \\
\hline$M_{2 \mathrm{is}}$ & 1.06 & $\operatorname{Re}_{2, C^{\prime}}{ }^{(*)}$ & $1.2 \times 10^{6}$ \\
\hline$\frac{M_{3 \text { ist }}}{2}$ & 0.89 & $\operatorname{Re}_{3 r, G r}\left(^{\left({ }^{*}\right)}\right.$ & $5.2 \times 10^{5}$ \\
\hline$\frac{M_{3 \text { is }}}{M_{4 \text { is }}}$ & $\frac{0.42}{0.68}$ & $\operatorname{Re}_{4, \mathrm{CS}}(\boldsymbol{N})$ & $4.8 \times 10^{5}$ \\
\hline
\end{tabular}

Fig. 13. 1.5 stage VKI turbine research rig operational conditions [16, 18] and two-layered "Senflex" thin film heat transfer gauge array attached to the suction side of the second stator [19]. 
turbine conditions [16-18]. Figure 12 shows the original facility configuration that consists of 43 trailing edge cooled guide vanes and a rotor system with 64 blades. The inset shows the modified turbine stage with the inclusion of a second stator system with 43 vanes. The second stator can be rotated in the azimuthal direction to investigate clocking effects. The tip clearance that has a weak variation from the leading edge to trailing edge is approximately $0.6 \%$ of the rotor blade height. The operational conditions of the turbine rig are summarized in Fig. 13.

The VKI turbine research rig benefits from both single layered deposited thin film sensors and two-layered gauges for unsteady heat flux signal acquisition. A two-layered "Senflex" thin film heat transfer gauge array attached on the suction side of the second stator is shown in Fig. 13. A successful implementation of this specific heat flux sensor array is explained in detail in [19]. Figure 14 presents unsteady Nusselt
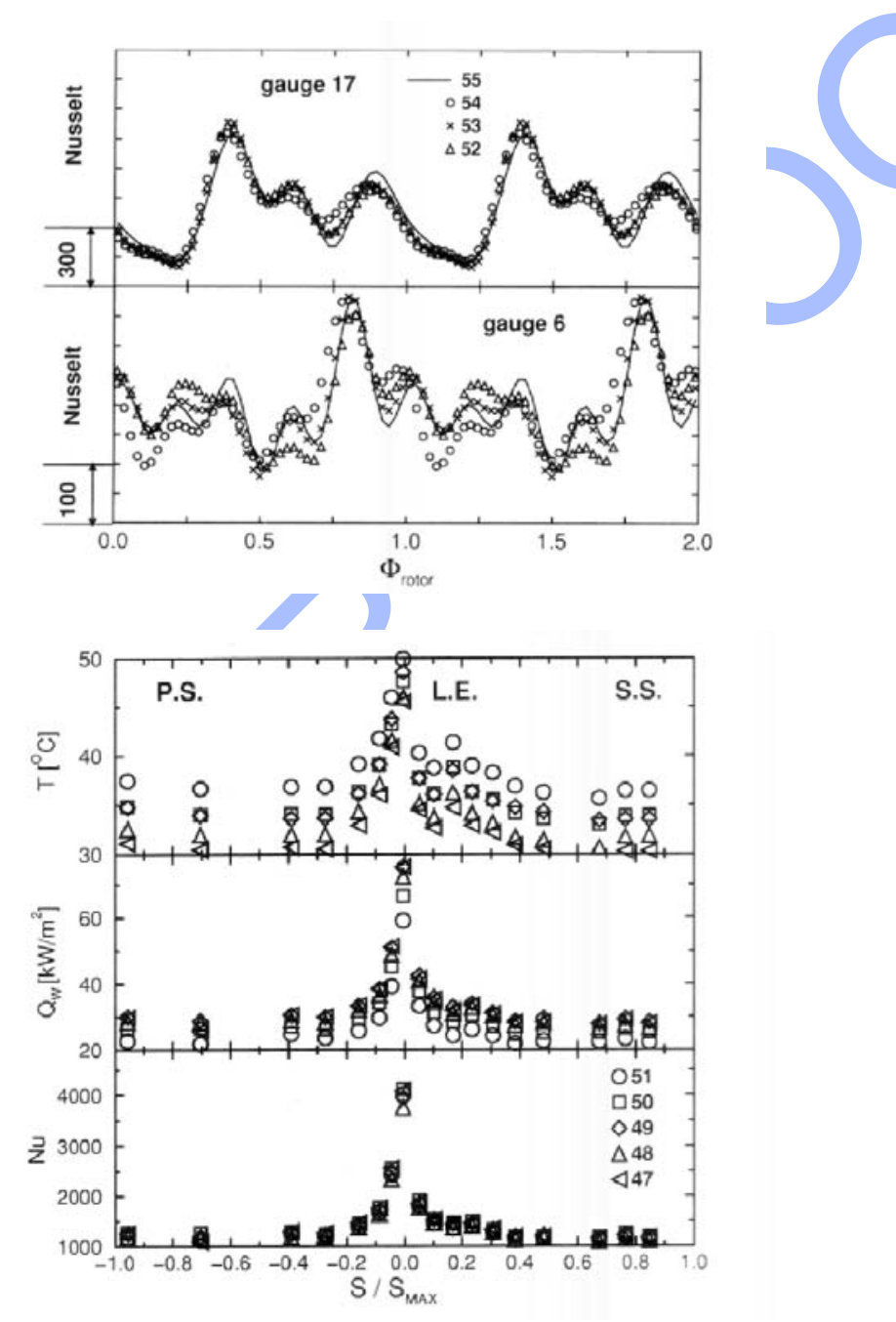

Fig. 14. Phase-locked unsteady heat transfer measurements and time-averaged heat transfer on the second stator of the VKI turbine research facility [19]. 
number traces in function of the rotor position from phase-locked heat transfer measurements performed on the second stator of the VKI turbine. The signals were obtained from two pressure side locations in the first $1 / 3$ chord region. Four different repeats from the two sensors indicate excellent repeatability. The results are ensemble averaged for three complete rotor revolutions or 192 rotor-passing events. Phaselocked measurement approach allows the researcher to extract the random unsteady part of the signal. Quantifying the wake passing and the potential interactions between the rotor and stator is of extreme importance when interpreting unsteady wall heating phenomena in transonic turbine stages. Figure 14 also shows the mean wall temperature, wall heat flux and heat transfer distribution on the pressure side and suction side of the second stator. The figure contains five different runs in the VKI turbine. Each run is obtained from a different initial wall temperature distribution in the rig. Since the turbine flow conditions are accurately repeated during each of the five individual experiments, the resulting Nusselt number distributions are almost the same as shown in Fig. 14.

A three-dimensional computational simulation of the VKI transonic turbine stage is discussed in [20]. Effect of the hub endwall cavity flow on the flow field of the VKI turbine stage is presented in [21]. The effect of clocking and its influence on the aerodynamic and mechanical behavior is investigated in [22].

\subsection{Short Duration Turbine Research Facility (TRF) at Wright Patterson Air Force Base}

Turbine Research Facility (TRF) at the Air Force Research Laboratory [23] is presented in Fig. 15. TRF is a transient "blow-down" rig capable of operating for peri-

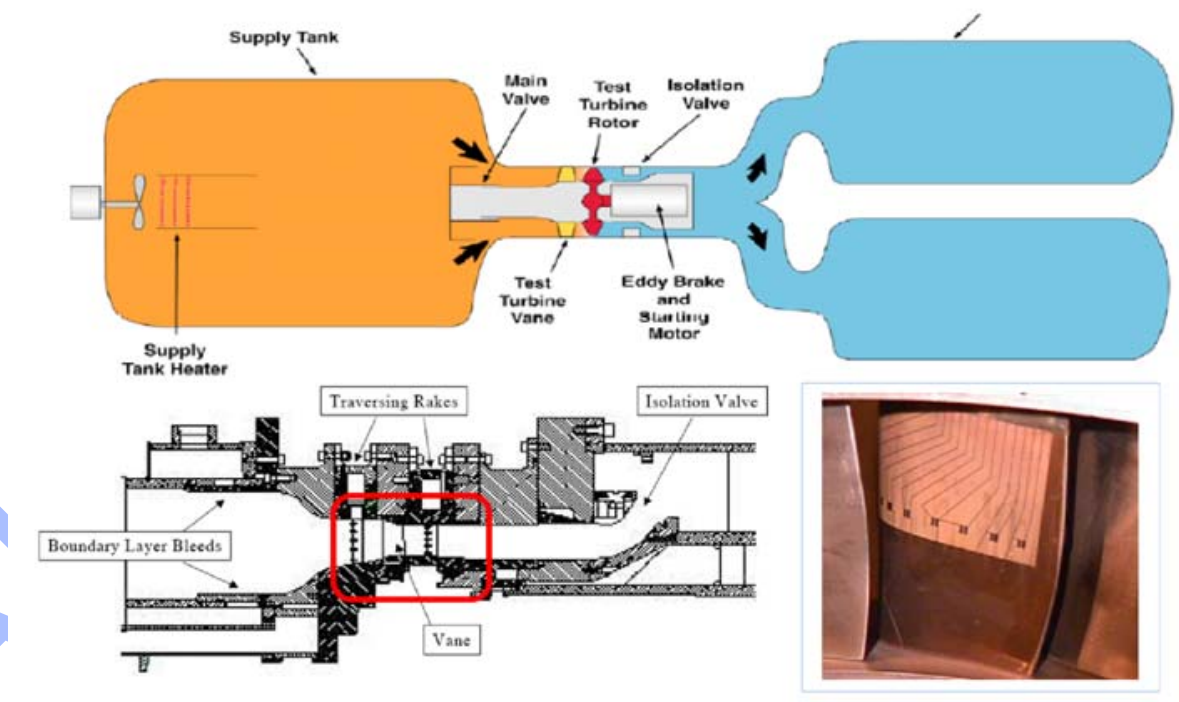

Fig. 15. Short duration turbine research facility (TRF) stage and vane suction side heat transfer instrumentation at Wright Patterson Air Force Base [23]. 
ods of several seconds at the correctly scaled Mach and Reynolds numbers of the turbines of actual engines. Before the start of a TRF test, the entire facility is evacuated and the fast acting valve between the supply tank and the test section is closed. Next, the supply tank can be filled with admixture of $\mathrm{N}_{2}$ and $\mathrm{CO}_{2}$ whose composition is set to simulate the same specific heat ratio $\gamma$ as that of combustion gases at the engine operating conditions. For most of the tests only nitrogen was used resulting in $\gamma=$ 1.4 and $\mathrm{a} \operatorname{Pr}=0.71$. This is reasonably close to the desired $\operatorname{Pr}$ of high temperature air, about 0.68 . Figure 15 also shows a vane suction side surface that was wrapped with a 50-micron thick film sheet of Upilex similar to the flexible substrate used at the VKI turbine facility. This sheet was wrapped from the trailing edge to trailing edge of a single vane creating no surface discontinuities along the airfoil surface [24]. Thirteen 0.04-micron thick platinum sensing elements were sputtered on top of the Upilex flexible substrate prior to installation on the vane suction side. The heat flux data from the gauges was determined by using the resistance change with time to a temperature trace via a calibration for resistance to temperature. The heat flux was then calculated based on the time rate of change of the surface temperature coupled with the thermal properties of the Pyrex or Upilex substrates.

\subsection{Ohio State University Turbine Research Facility}

This rotating turbine heat transfer facility utilized a shock-tunnel to produce a short-duration source of heated and pressurized gas that was passed through the turbine stage [25]. The experimental apparatus shown in Fig. 16 consisted of an air driven shock tube, an expansion nozzle, a dump tank and a test system that housed the turbine stage. The shock tube has a $0.47-\mathrm{m}$ diameter by $12.2-\mathrm{m}$ long driver tube and $0.47-\mathrm{m}$ diameter by $18.3-\mathrm{m}$ long driven tube. The driver tube was designed to be long enough so that the wave system reflected from the driver endwall would not terminate the test time prematurely. The turbine is housed in a device located in the expansion nozzle of the shock-tunnel facility as illustrated in Fig. 16. In order to start a heat transfer test sequence, the test section is evacuated while the driver and the

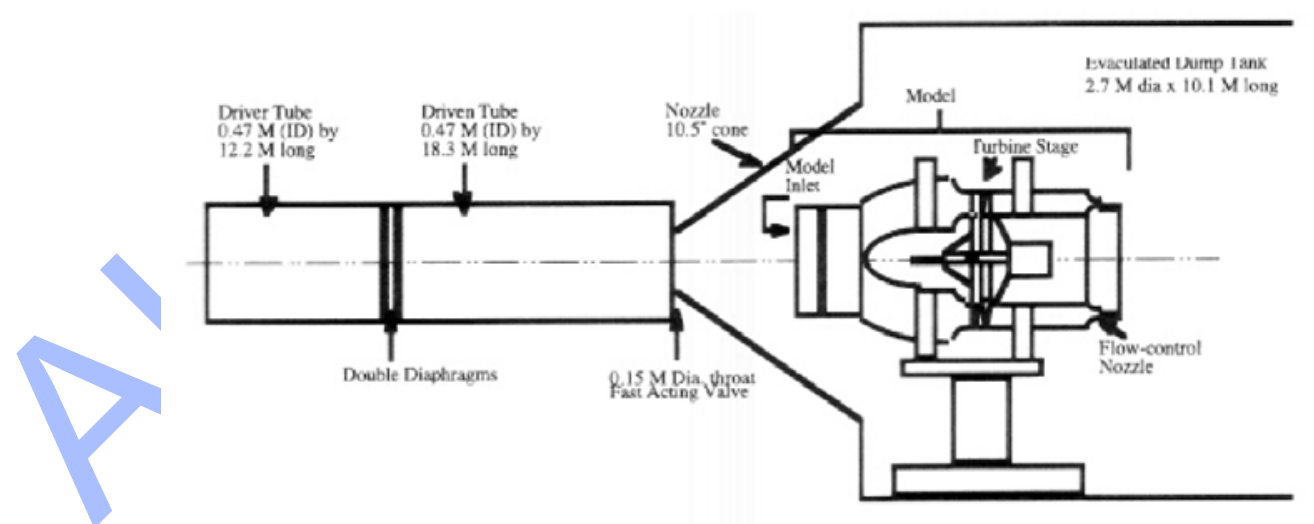

Fig. 16. Shock tube driven turbine test facility at the Ohio State University [25]. 
driven tube are pressurized to predetermined values. Pressure values are selected to duplicate the design flow conditions. The turbine flow function, wall-to-total temperature ratio, stage pressure ratios, and corrected speed are duplicated. The value of $T_{0}$ can be set at almost any desired value in the range of $800^{\circ} \mathrm{R}\left(171^{\circ} \mathrm{C}\right)$ to $3500^{\circ} \mathrm{R}$ $\left(1671^{\circ} \mathrm{C}\right)$. The pressure ratio across the turbine is established by altering the throat diameter of a flow control nozzle located near the exit end of the device housing the turbine [26]. The thin-film heat flux gauges were made of $(\sim 100 \AA$ thick $)$ platinum and were hand painted on an insulating Pyrex 7740 substrate. The response time of these thin films is in the order of $5 \times 10^{-8} \mathrm{~s}$. The turbine stage shown in Fig. 17 is a 1.5 stage (High-Pressure Turbine Vane-HPTV, High-Pressure Turbine Blade-HPTB, and Low-Pressure Turbine Vane-LPTV) turbine, configured in a manner that is representative of the highly 3D airfoil rows in a modern engine [26].
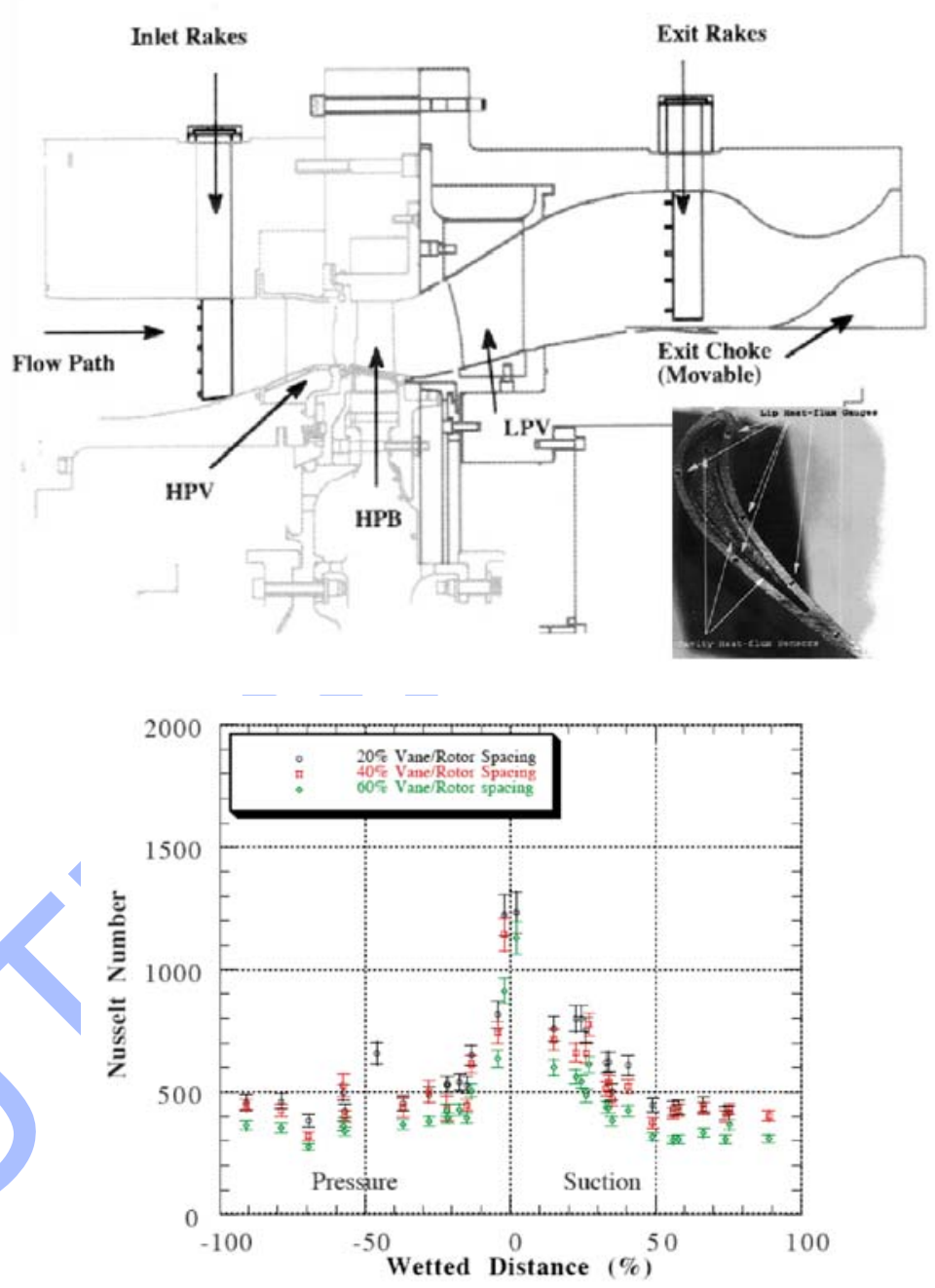

Fig. 17. 1.5 stage turbine stage at Ohio State University [26] and Nusselt number distribution [25]. 
The total pressure ratio across the rig is in excess of 5. The Ohio State turbine stage shown in Fig. 17 has 38 vanes (both HP and LP) and 72 blades. The exit choke is movable, so that a variety of pressure ratios are available. By controlling the pressure ratio across the stage, the inlet pressure, the corrected speed, and a wide variety of engine operating conditions can be replicated. The overall research effort performed in this rig was comprised of the aerodynamics of the turbine stage and unsteady heat transfer measurements performed around the rotor, rotor shroud and vane [26]. Molter et al. [27] recently presented heat-flux measurements and predictions from the blade tip region of this HP turbine.

\subsection{QinetiQ Light Piston Isentropic Compression Tube Driven Turbine Research Facility}

The QinetiQ Isentropic Light Piston Facility (ILPF) as shown in Fig. 18 is a short duration wind tunnel capable of "aero-heat transfer" testing of an engine size turbine at realistically simulated conditions [28]. This facility was originally used to test a single HP turbine stage. The facility was recently extended to 1.5 turbine stages with
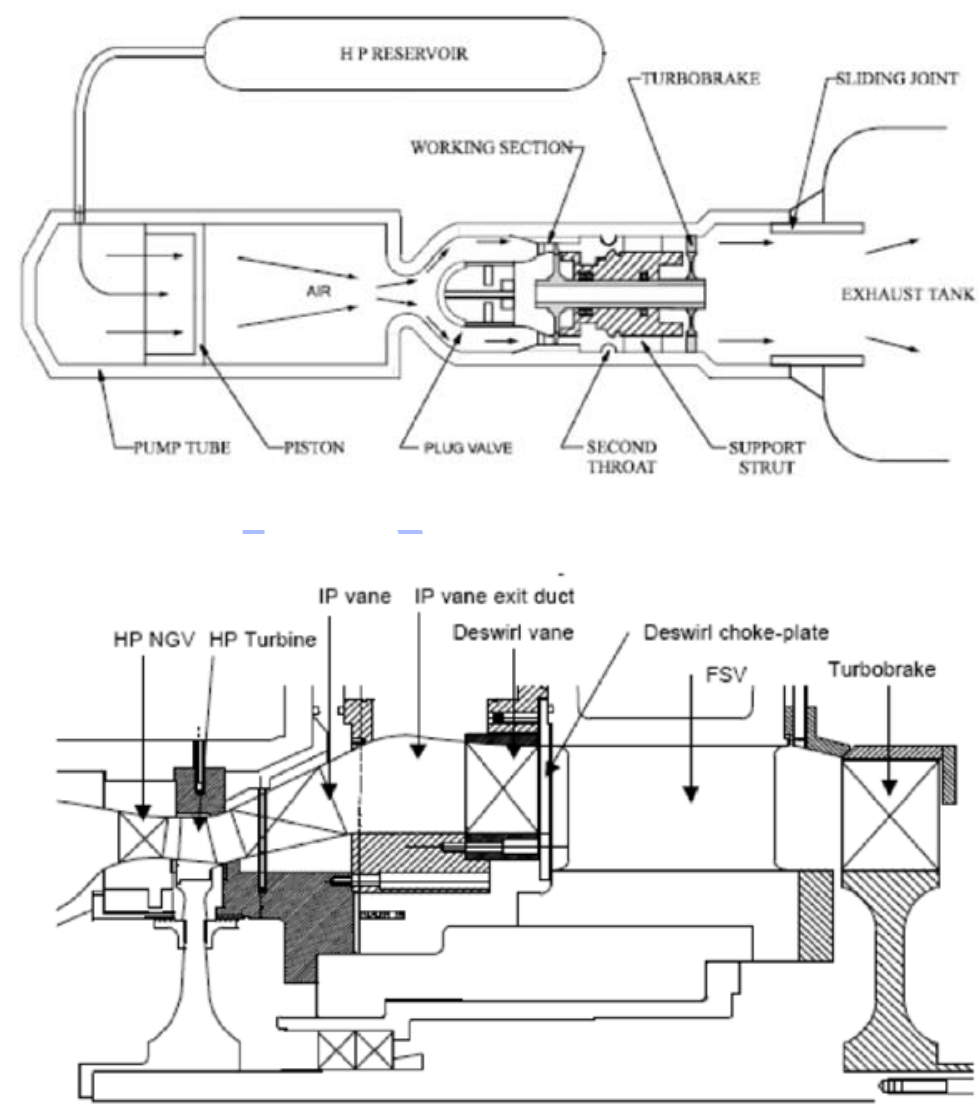

Fig. 18. QinetiQ short duration turbine stage [28]. 
the installation of an IP stator. A unique feature of the facility is the aerodynamic turbo-brake that is on the same shaft as the turbine and is driven by the turbine exitflow. At the design speed the turbo-brake power is matched with the turbine, and thus the turbo-brake maintains constant speed during a run as shown in Fig. 18. Air from a high-pressure reservoir moves a piston down a piston tube, isentropically compressing and heating the working gas (air) inside the tube. When the desired pressure is reached, the compressed air is suddenly released by means of a fast acting valve, into the working section. Steady-state turbine conditions are achieved for approximately $500 \mathrm{~ms}$. The turbine stage is a modern high pressure Rolls-Royce aero-engine design with stage pressure ratio of 3.2 and nozzle guide vane Reynolds number of $2.54 \times 10^{6}$. The stage is unshrouded and blade counts for the HP stator, HP rotor, and the IP stator are 32, 60 and 26, respectively [28].

\subsection{Low Speed Large Scale Turbine Rig at Texas A\&M University}

The three stage low speed and large scale research turbine is the core component of the "Turbomachinery Performance and Flow Research Facility" (TPFL) at Texas

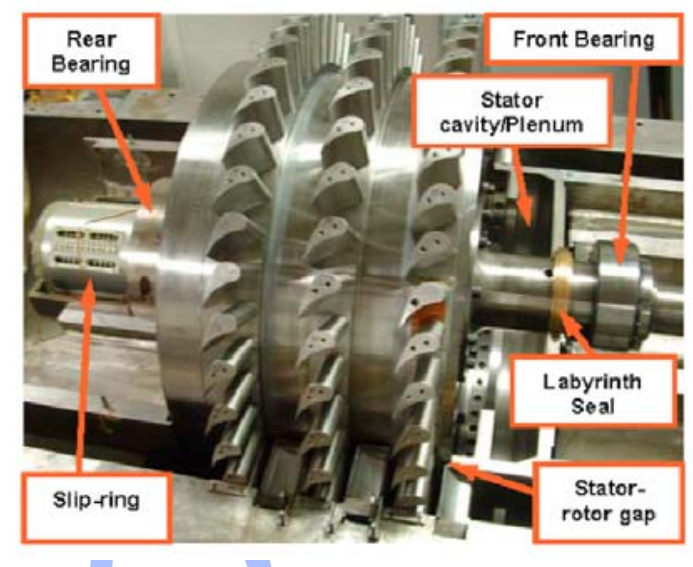

ㄴ.

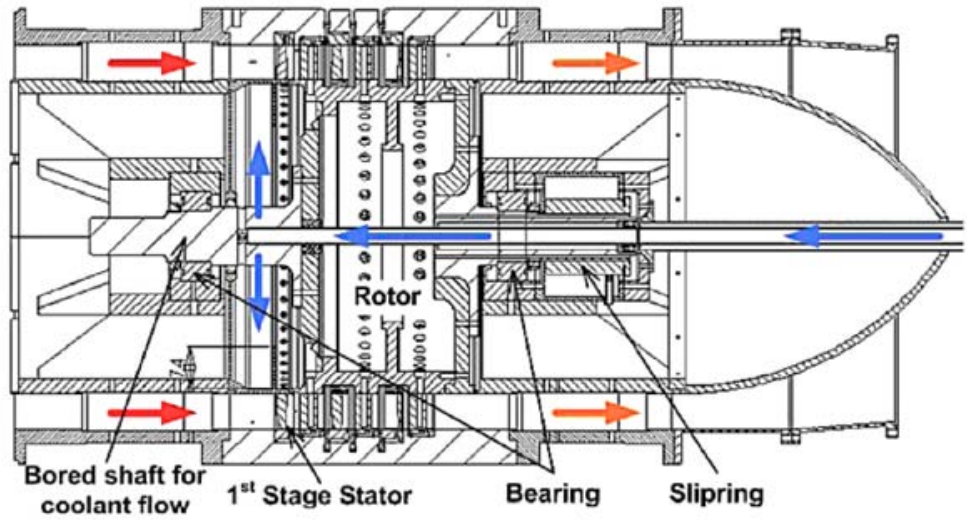

Fig. 19. Three-stage, low-speed large-scale turbine research facility at Texas A\&M Universit [30]. 
A\&M University. This facility, designed by Schobeiri [29] is used for aerodynamics, efficiency, performance, and heat transfer issues of high pressure, intermediate pressure, and low-pressure turbine components. The overall layout of the test facility is shown in Fig. 19 [30]. The rotational speed of this $0.685 \mathrm{~m}$ rotor can be adjusted between 1500 and $2550 \mathrm{rpm}$. The rotor rows have 46, 40, and 44 blades in a threestage arrangement, whereas the stator rows have 56, 52, and 48 airfoils. It consists of a $300 \mathrm{HP}$ inverter controlled electric motor that drives the three-stage compressor in suction mode with a maximum pressure difference of $55 \mathrm{kPa}$ and a volume flow rate of $4 \mathrm{~m}^{3} / \mathrm{s}$. The turbine inlet that has a heater section that is open to atmospheric conditions. The heater prevents condensation of water from humid air expanding through the turbine during the test. To determine the film cooling effectiveness under rotating conditions for leading edge film cooling, the turbine rotor was modified to integrate the coolant loop into the downstream section of the hollow turbine shaft and into the cylindrical hub cavity as described in [31]. This turbine rig is one of the first rotating facilities in which a pressure sensitive paint based film cooling effectiveness measurement technique is frequently and effectively employed.

\subsection{Axial Flow Turbine Research Facility AFTRF at Pennsylvania State University}

The Axial Flow Turbine Research Facility (AFTRF) at the Turbomachinery AeroHeat Transfer Laboratory is shown in Fig. 20. A recent description of the operational characteristics of this rotating rig designed mainly for aerodynamics and heat transfer investigations is available in [32]. The research facility is a large-scale, low speed, cold flow turbine stage depicting many characteristics of modern high-pressure turbine stages. The airflow through the facility is generated by a four stage axial fan located downstream of the turbine. The turbine rig has a removable casing segment for measurement convenience especially for casing and tip related aero-thermal studies. The relevant design performance data including reaction at blade hub and tip, Reynolds number at rotor exit, and a few blade parameters are also listed in Fig. 20. Measured/design values of rotor inlet flow conditions including radial, axial, tangential components and data acquisition details of the turbine rig are explained in detail in [32-34]. Instruments used for monitoring the performance parameters of AFTRF consist of total pressure probes, Kiel probes, static Pitot probes, thermocouples, and a precision in-line torque meter. The turbine rotational speed that is adjustable to $\pm 1 \mathrm{rpm}$ is kept constant around $1300 \mathrm{rpm}$ by means of an eddy current brake.

Figure 21 shows AFTRF rotor related aerodynamic details that can be highly influential in the determination of final wall heating patterns in axial turbines. A set of phase-locked LDA measurements clearly show the extent of tip vortical flow near the tip, wake pattern and rotor secondary flow structure. The middle figure presents the wall static pressure measurements performed near the blade tip in the rotating frame of reference. Although the measured suction side pressure coefficient agrees well with the RANS computations, the static pressure measurements near the pressure side corner where the tip leakage is significant show a discrepancy when compared to com- 


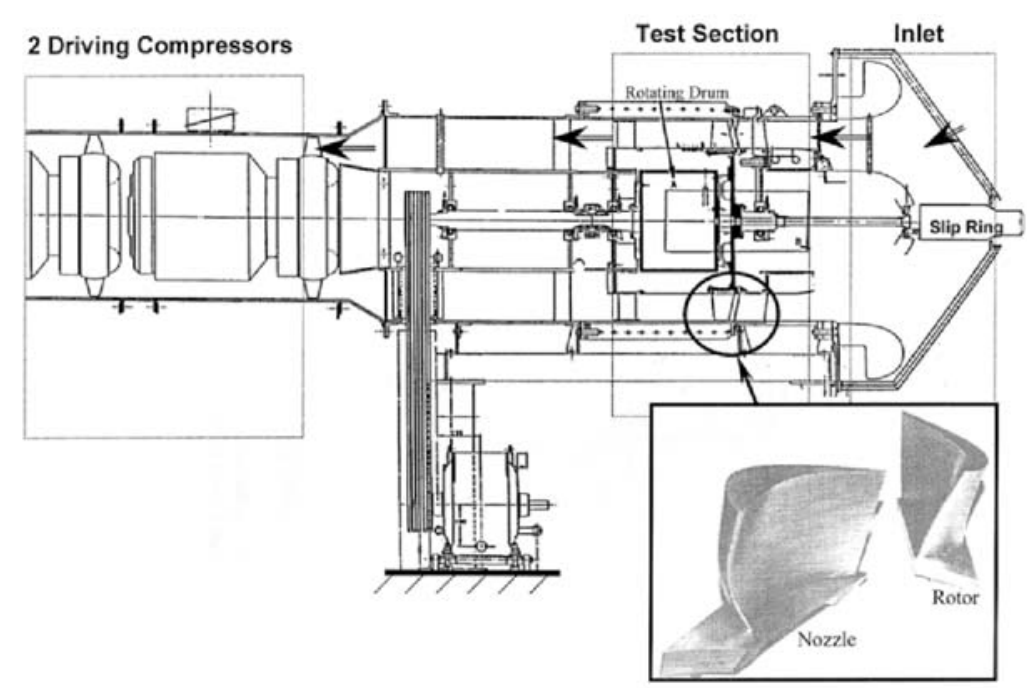

\begin{tabular}{|l|c|}
\hline Inlet Total Temperature: $\mathrm{T}_{\mathrm{ol}}(\mathrm{K})$ & 289 \\
\hline Inlet Total Pressure: $\mathrm{P}_{\mathrm{ol}}(\mathrm{kPa})$ & 101.36 \\
\hline Mass Flow Rate: $\mathrm{Q}(\mathrm{kg} / \mathrm{sec})$ & 11.05 \\
\hline Rotational Speed: $\mathrm{N}(\mathrm{rpm})$ & 1300 \\
\hline Total Pressure Ratio: $\mathrm{P}_{\mathrm{ol}} / \mathrm{P}_{03}$ & 1.077 \\
\hline Total Temperature Ratio: $\mathrm{T}_{\mathrm{o} 3} / \mathrm{T}_{\mathrm{ol}}$ & 0.981 \\
\hline Pressure Drop: $\mathrm{P}_{\mathrm{ol}}-\mathrm{P}_{\mathrm{o}}(\mathrm{mm} \mathrm{Hg})$ & 56.04 \\
\hline Power: $\mathrm{P}(\mathrm{kW})$ & 60.6 \\
\hline
\end{tabular}

\begin{tabular}{|l|c|}
\hline Rotor hub-tip ratio & 0.7269 \\
\hline Blade Tip Radius; $\mathrm{R}_{\text {tip }}(\mathrm{m})$ & 0.4582 \\
\hline Blade Height; $\mathrm{h}(\mathrm{m})$ & 0.1229 \\
\hline Relative Mach Number & 0.24 \\
\hline Number of Blades & 29 \\
\hline Axial Tip Chord; $(\mathrm{m})$ & 0.085 \\
\hline Spacing; $(\mathrm{m})$ & 0.1028 \\
\hline Turning Angle; Tip / Hub & $95.42^{\circ} / 125.69^{\circ}$ \\
\hline Nominal Tip Clearance; $(\mathrm{mm})$ & 0.9 \\
\hline Reaction, Hub / Tip & $0.197 / 0.519$ \\
\hline $\begin{array}{l}\text { Reynolds Number }\left(\div 10^{5}\right) \\
\text { inlet / exit }\end{array}$ & $(2.5 \sim 4.5) /(5 \sim 7)$ \\
\hline
\end{tabular}

Fig. 20. Axial Flow Turbine Research Facility, AFTRF, at Pennsylvania State University, Turbomachinery Aero-Heat Transfer Laboratory [32, 34].

putational results. This may be attributed to the highly strained and separated relative flow pattern existing in this region where static holes may see leakage flow partially impinging on them. Finally, the rotor exit mid-span turbulence intensity in the circumferential direction shows that high levels of free stream turbulence ranging from $10 \%$ to $35 \%$ in the wake are typical near the rotor exit plane.

The most recent aero-heat transfer research in the AFTRF is focused on the tip region and the casing region. Figure 22 presents the casing heat transfer measurement 

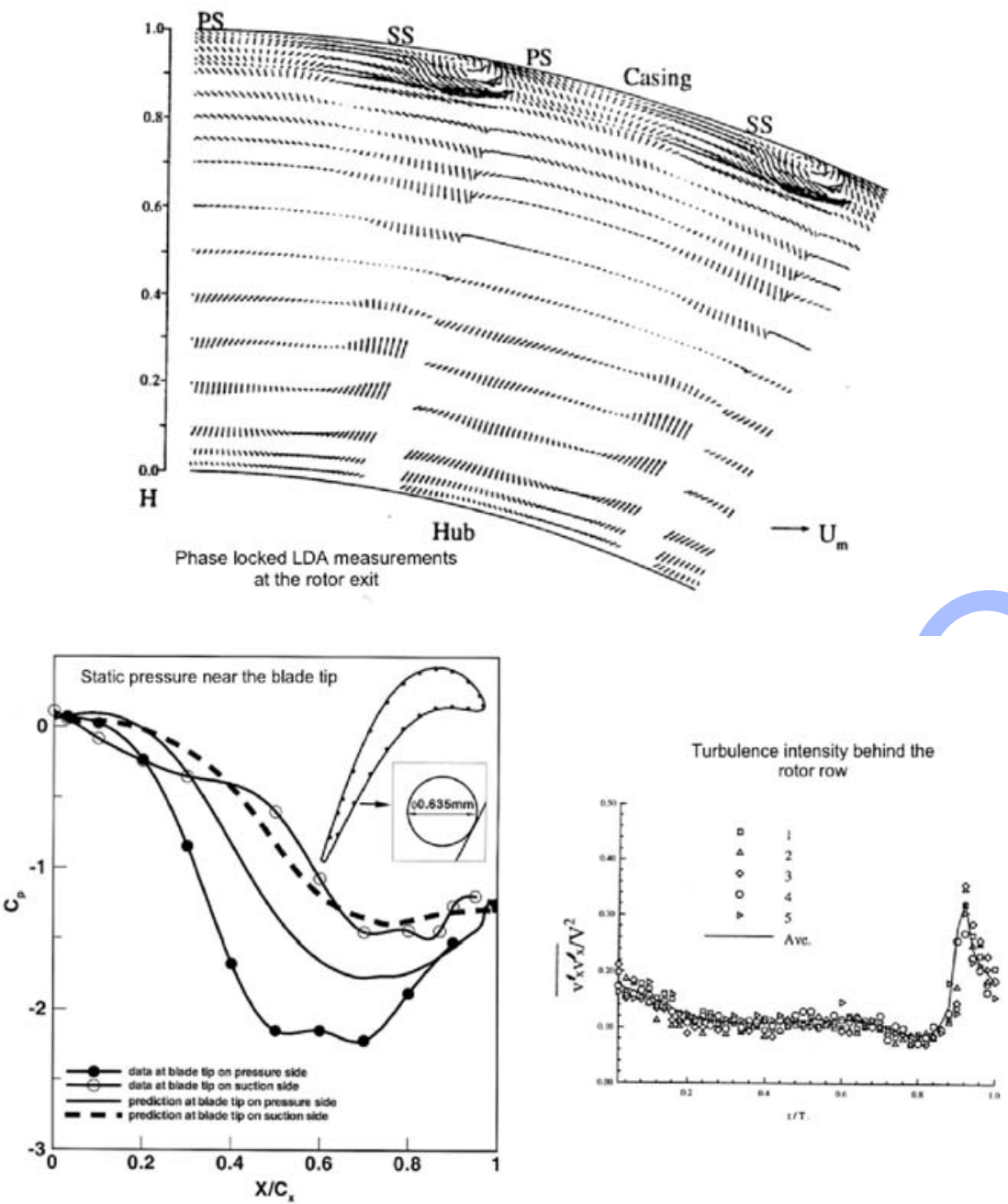

Fig. 21. Rotor exit flow field, rotor tip static pressure and rotor exit axial turbulence intensity in AFTRF, PSU Turbomachinery Aero-Heat Transfer Laboratory $[32,34]$.

system which is mounted on the flow side of the "turbine access window" flush mounted in the research rig. This system was developed for measuring convective heat transfer coefficients on various "patterned" casing surfaces covering the rotating blade tip area. The flow side of the casing plate is flush-mounted with the rest of the inner part of the AFTRF casing. The axial distribution of the heat transfer coefficient is measured with an estimated uncertainty level between $5 \%$ and $8 \%$ of convective heat transfer coefficient $h$ [35].

The heat transfer results shown in Fig. 23 are obtained by a 3D heat loss analysis in order to reduce the measurement uncertainties. A 3D heat conduction analysis in the casing window and the casing plate is simultaneously conducted. The reference free stream temperature for this turbine convective heat transfer problem is the "adi- 

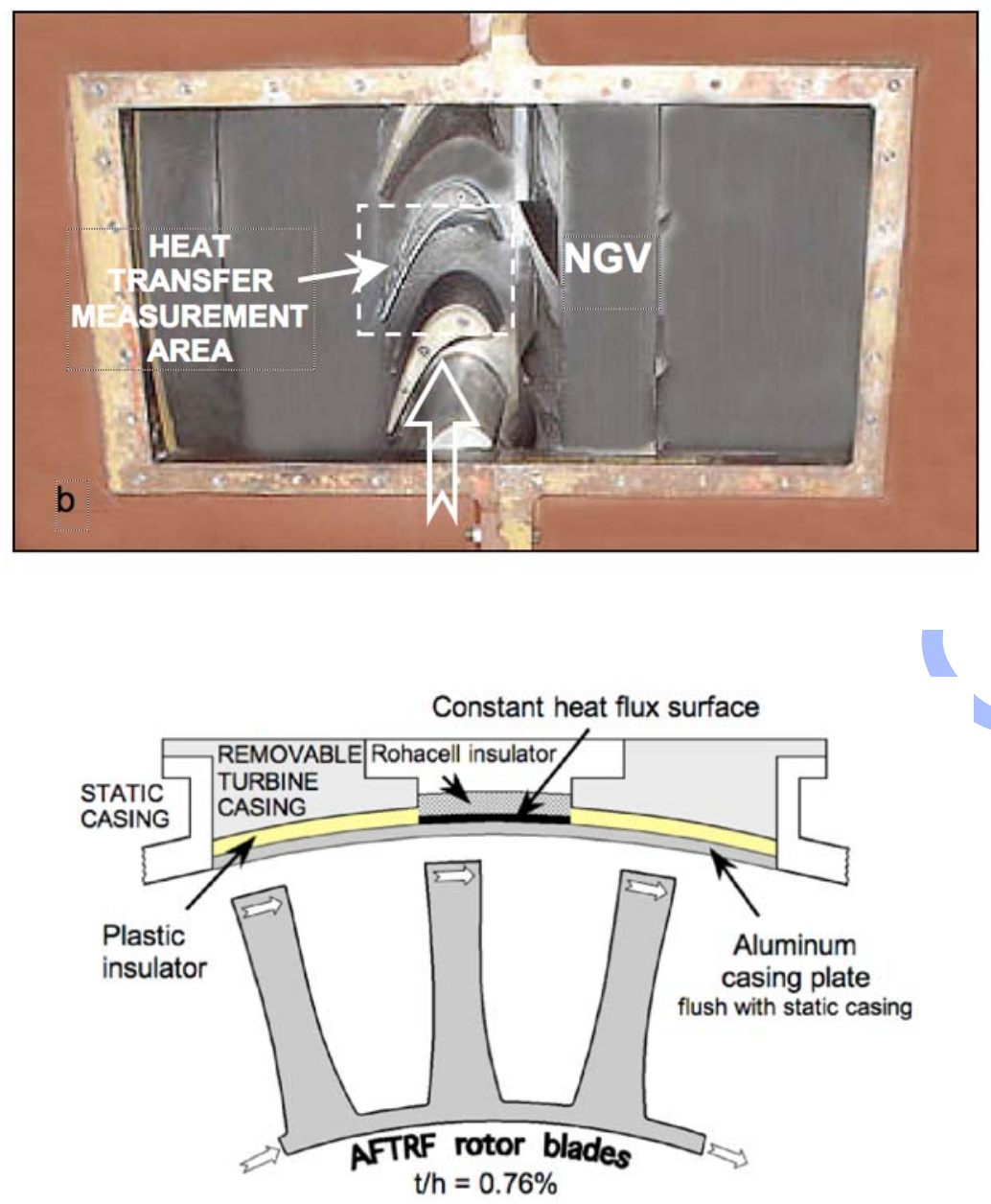

Fig. 22. Heat transfer measurements using a constant heat transfer surface near the casing in AFTRF, Turbomachinery Aero-Heat Transfer Laboratory [35].

abatic wall temperature" $T_{\mathrm{f}}=T_{\mathrm{aw}}$. Due to energy extraction from the working fluid in a turbine, the total temperature is continuously reduced in axial direction. Therefore, an accurate method of obtaining the true reference temperature (adiabatic wall temperature) is needed. Figure 23 shows the results of recent experiments when the power setting of the constant heat flux surface is continuously changed in order to obtain the local "adiabatic wall temperature", at a selected axial measurement position. The dramatic influence of working with the correct reference temperature in an axial turbine rotor environment is apparent in the middle part of Fig. 23. The adiabatic wall temperature is a strong function of the axial position in the rotor frame of reference and it needs to be measured accurately in order to keep heat transfer coefficient uncertainties in the 5-8\% error band [35]. 

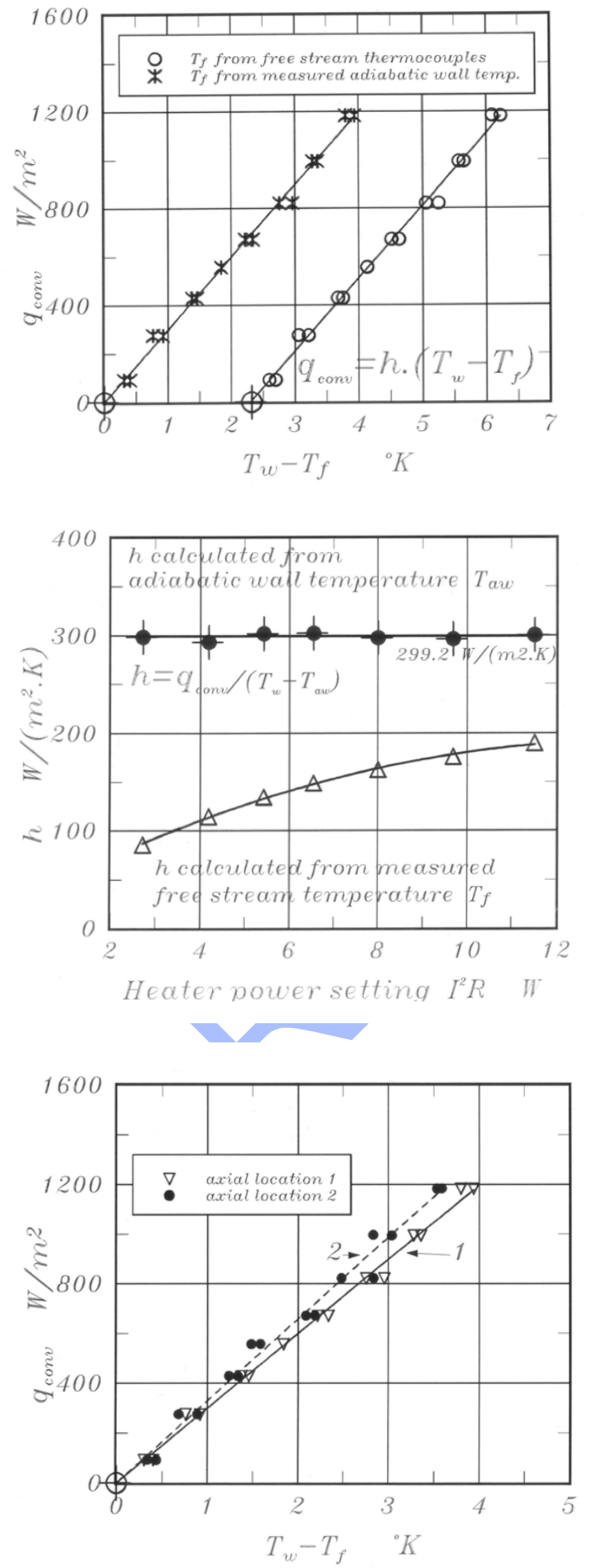

Fig. 23. Determination of the adiabatic wall temperature and heat transfer coefficient on the casing surface of AFTRF [35]. 


\section{CONCLUDING REMARKS}

The present paper dealt with the experimental aero-heat transfer studies performed in rotating turbine research facilities. Since the full-scale operational conditions of modern gas turbines dictate high temperatures in excess of $3600^{\circ} \mathrm{F}$ and pressure ratios ranging from 20 to 50, experimental forced convection heat-transfer research on the gas side of a rotating turbine is a technically challenging task. The current paper provided a brief review of turbine heat transfer research in various facilities that contained a rotor, including short-duration blow-down and large-scale/low-speed turbine systems. Since the final status of any forced convection heat transfer problem is closely related to the detailed structure of momentum transfer in highly unsteady, rotating, 3D and turbulent viscous flow environment, emphasis was also placed on supporting turbine aerodynamics research. After a discussion on the proper scaling of gas turbine convective heat transfer problem, the rotating facilities that produced heat transfer information were briefly described. Discussed heat transfer information was selected from the most recent publication in the open literature. Due to the excessive amount of information available in this field, only a few selected studies were discussed throughout the paper. The rotating turbine research rigs performing "only" stage aerodynamics/performance measurements, disk cavity flow experiments, rotating coolant passage experiments, turbine seal flow experiments were excluded from this heat transfer focused publication.

\section{NOMENCLATURE}

$\begin{array}{ll}c_{p} & \text { local specific heat } \\ c_{p_{0}} & \text { specific heat under reference conditions } \\ c_{p}^{*} & \text { nondimensional specific heat, } c_{p} / c_{p 0} \\ k & \text { local thermal conductivity } \\ k_{0} & \text { thermal conductivity under reference conditions } \\ k^{*} & \text { nondimensional thermal conductivity, }=k / k_{0} \\ L & \text { reference length } \\ p & \text { pressure } \\ p_{0} & \text { reference static pressure } \\ p^{*} & \text { nondimensional static pressure, }=\left(p-p_{0}\right) / \rho_{0} V_{0}^{2} \\ \operatorname{Pr} & \text { Prandtl number, }=\mu c_{p} / k \\ \operatorname{Re} & \text { Reynolds number, }=V_{0} L / \mu_{0} \\ \mathrm{St} & \text { Strouhal number, }=f L / V \\ T & \text { temperature } \\ T_{0} & \text { reference temperature } \\ T_{\mathrm{w}} & \text { wall temperature } \\ T_{\infty} & \text { free-stream total temperature }(\mathrm{gas} \text { temperature }) \\ T^{*} & \text { nondimensional temperature, }=\left(T-T_{0}\right) /\left(T_{\mathrm{w}}-T_{0}\right)\end{array}$




$\begin{array}{ll}t & \text { time } \\ t^{*} & \text { nondimensional time, }=t V_{0} / L \\ V_{i} & \text { velocity component, } u, v, w \\ V_{i}^{*} & \text { nondimensional velocity component, }=V_{i} / V_{0} \\ V_{0} & \text { reference velocity } \\ x_{i} & \text { independent space variable }\end{array}$

\section{Greek symbols}

$\lambda$

$\mu$

$\mu_{0}$

$\mu^{*}$

$v$

$v_{0}$

$\rho$

$\rho_{0}$

$\rho^{*}$

$\Phi$

$\Phi^{*}$ second coefficient of viscosity

absolute viscosity

reference viscosity

nondimensional viscosity, $=\mu / \mu_{0}$

kinematic viscosity

reference kinematic viscosity

local density

density under reference conditions

$=\rho / \rho_{0}$

viscous dissipation function

nondimensional dissipation function, $=L^{2} \Phi / \mu_{0} V_{0}^{2}$.

\section{REFERENCES}

1. Bunker, R. S. Gas turbine heat transfer: 10 remaining hot gas path challenges, ASME paper GT2006-90002, (2006).

2. Dunn, M. G. Convective heat transfer and aerodynamics in axial flow turbines, 2001 IGTI Scholar Lecture also, ASME J. Turbomachinery, 2001, Vol. 123, [Q7]

3. Epstein, A., Guenette, G. R., and Norton, R. J. G. The Design of the MIT Blow down Turbine Facility, MIT GTL Report No. 183, 1985.

4. Case, L. Proposed Turbine/Fan Model, Blow down Test Facility, UTRC Report 727-7550, 1985.

5. Epstein, A., Guenette, G. R. and Norton, R. J. G. The MIT blow down turbine facility, ASME Paper 84-GT-116, 1984.

6. Abhari, R. S., Guenette, A. H., Epstein, A. H., and Giles, M. B. Comparison of time resolved turbine rotor blade heat transfer measurements and numerical calculations, ASME Paper 91-GT-268, 1991.

7. Dring, R. P. and Joslyn, H. D. Measurements of rotor blade flows, ASME J. Eng. Power, 1981, Vol. ?, pp. ? -- ? [Q7]

8. Blair, M. F., Dring, R. P. and Joslyn, H. D. The effects of turbulence and stator-rotor interactions on turbine heat transfer. Part I: Design operating conditions, ASME Paper 88-GT-125, 1988.

9. Blair, M. F., Dring, R. P., and Joslyn, H. D. The effects of turbulence and stator-rotor interactions on turbine heat transfer. Part II: The effects of reynolds number and incidence, ASME Paper 88-GT-5, 1988. 
10. Sharma, O. P., Pickett, G. F., and Ni, R. H. Assessment of unsteady flows in turbines, ASME paper 90-GT-150, 1990.

11. Blair, M. F., Wagner, J. H., and Steuber, G. D. New applications of liquid crystal thermography in rotating turbomachinery heat transfer research, ASME Paper 91-GT-354, 1991.

12. Schultz, D. L., Jones, T. V., Oldfield, M. L. G., and Daniels, L. C. A New Transient Cascade Facility for the Measurement of Heat Transfer Rates, AGARD CP-229, 1977.

13. Hilditch, M. A. and Ainsworth, R. W. Unsteady heat transfer measurements on a rotating gas turbine blade, ASME Paper 90-GT-175, 1990.

14. Ainsworth, R. W., Schultz, D. L., Davies, M. R. D., Forth, C. J. P., Hilditch, M. A., and Oldfield, M. L. G. A transient flow facility for the study of the thermofluid-dynamics of a full stage turbine under engine representative conditions, ASME Paper 88-GT-144, 1988.

15. Allan, W., Ainsworth, R., and Thorpe, S. Unsteady heat transfer measurements from transonic turbine blades at engine representative conditions in a transient facility, ASME paper GT2004-53835, 2004.

16. Sieverding, C. H. and Arts, T. The VKI compression tube annular cascade facility, ASME Paper 92-GT-33, 1992.

17. Dénos, R. Aero-Thermodynamic Investigation of the Unsteady Flow in a Transonic Turbine Rotor, Doctoral Thesis, von Karman Institute for Fluid Dynamics/University of Poitiers, 1996.

18. Sieverding, C. H., Dénos, R., Arts, T., Brouckaert, J. F., and Paniagua, G. Experimental Investigation of the Unsteady Rotor Aerodynamics and Heat Transfer of a Transonic Turbine Stage, VKI Lecture Series on Blade Row Interference Effects in Axial Turbomachinery Stages, 1998.

19. Illiopoulou, V., Denos, R., Billiard, N., and Arts, T. Time-averaged and time-resolved heat flux measurements on a turbine stator blade using two-layered thinfilm gauges, ASME J. Turbomachinery, 2004, Vol. 126,[Q7].

20. Michelassi, V., Giangiacomo, P., Martelli, F., Dénos, R., and Paniagua, G. Steady three-dimensional simulation of transonic axial turbine stage, ASME Paper 2001-GT-0174, 2001.

21. Paniagua, G., Dénos, R., and Almeida, S. Effect of the hub endwall cavity flow on the flow-field of a transonic high-pressure turbine, ASME Paper GT200453458, 2004.

22. Gadea, J., Dénos, R., Paniagua, G., Billiard, N., and Sieverding, C. H. Effect of clocking on the second stator pressure field of a one and half stage transonic turbine, ASME Paper GT2004-53463, 2004.

23. Haldeman Jr., C. W., Dunn, M. G., MacArthur, C. D., and Murawski, C. G. The USAF Advanced Turbine Aerothermal Research Rig (ATARR), AGARD CP-319, 1992. 
24. Polanka, M. and Meininger, M. Installation effects on heat transfer measurements for a turbine vane, ADM001490, presented at RTO Applied Vehicle Technology Panel (AVT) Symposium held in Leon, Norway, 2001.

25. Dunn, M. G. and Haldeman, C. W. Time-averaged heat flux for a recessed tip, lip, and platform of a transonic turbine blade, ASME Paper 2000-GT-0197, 2004.

26. Haldeman, C. W., Dunn, M. G., Barter, J. W., Green, B. R., and Bergholz, R. F. Aerodynamic and heat-flux measurements with predictions on a modern one and 1/2 stage high pressure transonic turbine, ASME Paper GT2004-53478, 2004.

27. Molter, S. M., Dunn, M. G., Haldeman, C. W., Bergholz, R. F., and Vitt, P. Heat-flux measurements and predictions for the blade tip region of a high pressure turbine, ASME Paper GT2006-90048, 2006.

28. Chana, K., Hurrion, J., and Ones, T. The design development and testing of a non-uniform inlet temperature generator for the QinetiQ transient turbine test facility, ASME Paper 2003-GT-38469, 2003.

29. Schobeiri, M. T., Gilarranz, J. L., and Johansen, E. S. Aerodynamic and performance studies of a three stage high pressure research turbine with 3-d blades, design points and off-design experimental investigations, ASME Paper 2000-GT484, 2000.

30. Suryanarayanan, A., Mhetras, S. P., Schobeiri, M. T., and Han, J. C. Film-cooling effectiveness on a rotating blade platform, ASME Paper 2006-90034, 2006.

31. Ahn, J., Schobeiri, M. T., Han, J. C., and Moon, H. K. Film cooling effectiveness on the leading edge of a rotating film-cooled blade using pressure sensitive paint, ASME Paper GT-2005-68344, 2005.

32. Camci, C., Experimental and Computational Methodology for Turbine Tip Desensitization, VKI Lecture Series 2004-02, Turbine Blade Tip Design and Tip Clearance Treatment, 2004.

33. Rao, N. and Camci, C. Axial turbine tip desensitization by injection from a tip trench. Part 1: Effect of injection mass flow rate, ASME Paper GT2004-53256, 2004.

34. Lakshminarayana, B., Camci, C., Halliwell, I., and Zaccaria, M. Design and development of a turbine research facility to study rotor-stator interaction effects, Int. J. Turbo Jet Engines, 1996, Vol. 13, pp. 155-172.

35. Gumusel, B. and Camci, C. Casing convective heat transfer coefficient and reference free-stream temperature determination near an axial flow turbine rotor, ASME J. Heat Transfer, 2010, Vol. 133, pp. 14-22.

[Q8] Schobeiri, M. T., Suryanarayanan A., Jermann, C., and Neuenschwander, T. A Comparative aerodynamic and performance study of a three-stage high pressure turbine with 3-D bowed blades and cylindrical blades, ASME Paper GT-200453650, 2004. 
[Q7] Suryanarayanan, A., Ozturk, B., Schobeiri, M. T., and Han, J. C. Film-cooling effectiveness on a rotating turbine platform using pressure sensitive paint technique, ASME Paper 2007-27127, 2007.

[Q1] Au: Please check whether this sentence was corrected rightly.

[Q2] Something is missing here. Please, check.

[Q3] Can this be Fig.5, since Fig. 5 is missing?

[Q4] Can this be Fig. 7, as the mention of it is missing.

[Q5] Complete the reference, please.

[Q6] The reference is not cited in the text. Advise, please.

[Q7] The reference is not cited in the text. Advise, please. 